\title{
Hypervelocity Spherically-Blunted Cone Flows in Mars Entry Ground Testing
}

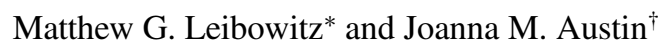 \\ California Institute of Technology, Pasadena, California 91125
}

https://doi.org/10.2514/1.J060162

\begin{abstract}
Bow-shock standoff distances over sphere and spherically-blunted cone geometries were examined through experiments in two facilities capable of high-stagnation enthalpy hypersonic flows simulating Mars planetary entry conditions. High-speed and high-resolution schlieren images were obtained in the California Institute of Technology T5 reflected shock tunnel and the Hypervelocity Expansion Tube to examine facility independence of the measurements. Accompanying reacting Navier-Stokes simulations were carried out. A recently developed unified model for sphere and sphere-cone behavior was first verified for high-stagnation enthalpy $\mathrm{CO}_{2}$ flows through simulations with thermal and chemical nonequilibrium. Shock standoff distance measurements in both facilities were found to be in good agreement with model predictions. The need to account for the divergence of the streamlines in conical nozzles was highlighted and an existing model extended to account for changes in shock curvature between parallel and conical flows. The contributions of vibrational and chemical nonequilibrium to the stagnation-line density profile were quantified using the simulation results comparing three chemical kinetic models.
\end{abstract}

\section{Nomenclature}

$A_{f} \quad=$ pre-exponential constant, $\mathrm{cm}^{3} /(\mathrm{mol} \cdot \mathrm{s})$ or $\mathrm{cm}^{6} /\left(\mathrm{mol}^{2} \cdot \mathrm{s}\right)$

$A_{\tau_{\nu}} \quad=$ Landau-Teller constant

$a_{i_{\nu}} \quad=$ sound speed, $\mathrm{m} / \mathrm{s}$

$C_{p} \quad=$ specific heat at constant pressure, $\mathrm{MJ} /(\mathrm{kg} \cdot \mathrm{K})$

$D \quad=$ base diameter, $\mathrm{m}$

$E_{a} \quad=$ activation energy, $\mathrm{K}$

$e \quad=$ specific internal energy, $\mathrm{MJ} / \mathrm{kg}$

$h \quad=$ specific enthalpy, $\mathrm{MJ} / \mathrm{kg}$

$h_{0} \quad=$ stagnation enthalpy, $\mathrm{MJ} / \mathrm{kg}$

$k_{b}=$ backward rate constant, $\mathrm{cm}^{3} /(\mathrm{mol} \cdot \mathrm{s})$ or $\mathrm{cm}^{6} /$ $\left(\mathrm{mol}^{2} \cdot \mathrm{s}\right)$

$k_{f}=\quad=$ forward rate constant, $\mathrm{cm}^{3} /(\mathrm{mol} \cdot \mathrm{s}) \operatorname{or~cm}^{6} /\left(\mathrm{mol}^{2} \cdot \mathrm{s}\right)$

$L=$ empirical parameter

$L_{0} \quad=$ distance from virtual origin to the shock, $\mathrm{m}$

Ma = Mach number

$n=$ number of species

$P \quad=$ pressure, $\mathrm{kPa}$ or $\mathrm{MPa}$

$q \quad=$ general nonequilibrium variable

$R \quad=\quad$ body radius, $\mathrm{m}$

$\boldsymbol{R}=$ specific gas constant, $\mathrm{J} /(\mathrm{kg} \cdot \mathrm{K})$

$R_{s} \quad=$ shock radius of curvature, $\mathrm{m}$

$r_{n} \quad=$ nose radius, $\mathrm{m}$

$r_{s}=$ sphere-cone shoulder radius, $\mathrm{m}$

$T=$ translational-rotational temperature, $\mathrm{K}$

$T_{a} \quad=$ geometrically averaged effective temperature, $\mathrm{K}$

$T_{V} \quad=\quad$ vibrational-electronic temperature, $\mathrm{K}$

$u \quad=$ velocity, $\mathrm{m} / \mathrm{s}$

$x=$ distance along stagnation streamline from the shock, $m$

$Y \quad=$ mass fraction

Presented as Paper 2018-1721 at the 2018 AIAA Aerospace Sciences Meeting, AIAA SciTech Forum, Kissimmee, FL, January 8-12, 2018; received 17 September 2020; revision received 17 January 2021; accepted for publication 18 March 2021; published online 27 July 2021. Copyright ( 2021 by California Institute of Technology. Published by the American Institute of Aeronautics and Astronautics, Inc., with permission. All requests for copying and permission to reprint should be submitted to CCC at www. copyright.com; employ the eISSN 1533-385X to initiate your request. See also AIAA Rights and Permissions www.aiaa.org/randp.

*Currently Senior Professional Staff, Aerospace and Mechanical Engineering Group, Johns Hopkins Applied Physics Laboratory, Laurel, Maryland 20723. Member AIAA.

†Professor of Aerospace, Graduate Aeronautical Laboratories. Associate Fellow AIAA.

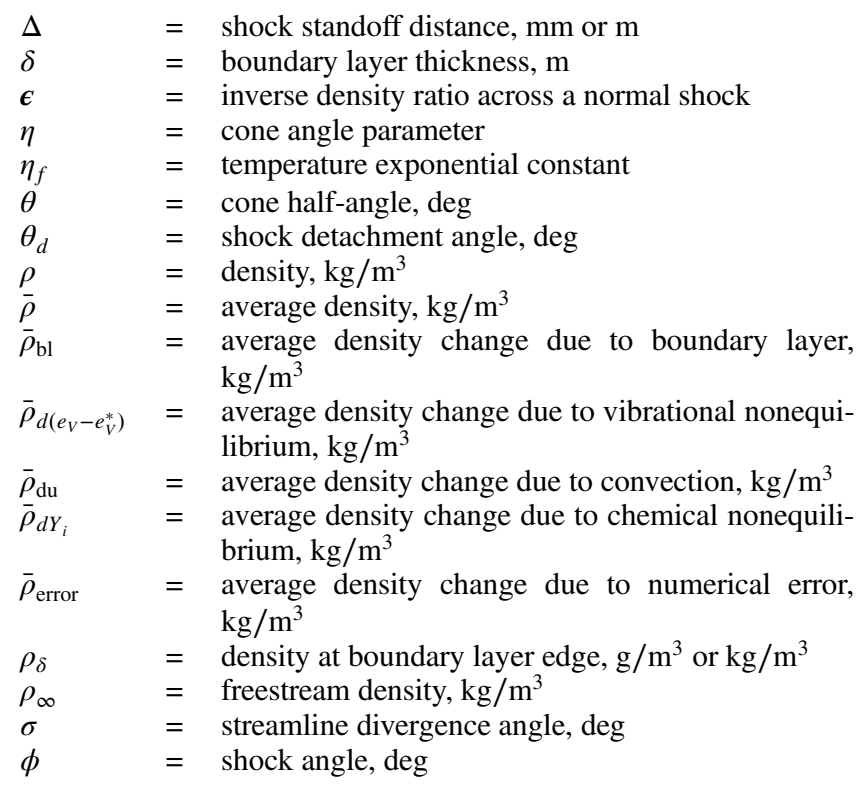

Subscripts

$\begin{array}{ll}c & =\text { conical flow } \\ i & =\text { species index } \\ p & =\text { parallel flow } \\ s & =\text { vibrationally frozen post-shock condition } \\ V & =\text { vibrational-electronic }\end{array}$

Superscript

* $\quad=$ thermal equilibrium

\section{Introduction}

D URING planetary entry, strong shock compression and high post-shock temperatures lead to significant chemical dissociation and vibrational excitation in the shock layer in front of a spherecone capsule, particularly near the stagnation region. For Mars missions, accurate thermochemical modeling of carbon dioxide, a principal component of the atmosphere with complex vibrational energy exchange, is particularly important. For spheres and cylinders in hypersonic flow in the limits of perfect gas or equilibrium postshock conditions, the shock standoff distance $\Delta$ can be shown to be a function of the normal shock inverse density ratio $\boldsymbol{\epsilon}$ 


$$
\frac{\Delta}{R_{s}}=L \epsilon
$$

where $\boldsymbol{\epsilon}=\rho_{\infty} / \rho_{s}, R_{s}$ is the shock radius, and $L$ is a constant of proportionality [1-4]. For nonequilibrium flows, where density increases due to dissociation behind the shock, a correlation for bow-shock shape and standoff distance with the integrated density along the stagnation streamline was proposed by Stulov on the basis of extensive numerical simulations for various body shapes [5]. Independently, Wen and Hornung applied the conservation of mass to a control volume around the stagnation streamline and found that the aforementioned expression is valid for nonequilibrium shock layers if the post-shock density is replaced by a representation of the changing density profile, such as the average density $\bar{\rho}$, while the radial velocity is assumed to be constant [6]. Stulov's and Wen and Hornung's results indicate that for spheres, the body radius $R$ can be used as the length scale and the correlation of Eq. (1) can be applied to nonequilibrium flows using the average streamline density and a value of $L=0.82$ [6] to 0.83 [5] (interpolated from Stulov's Fig. 2).

The shock standoff distance is thus a flow length scale that is sensitive to changes in the stagnation streamline density profile due to thermal and chemical nonequilibrium processes. Experimental measurements of shock standoff distance are useful for thermochemical model validation, although discrimination between models can be limited by the range and resolution of the experimental measurements in ballistic ranges and by uncertainty in freestream conditions in impulse facilities.

Spherically-blunted entry vehicle geometries exhibit a rapid transition from sphere behavior to cone behavior, corresponding to a jump in the sonic-line location and increase in the standoff distance, with increasing inverse density ratio across the shock. The sudden movement in sonic-line location was predicted and observed to lead to a pitch instability in the Mars Pathfinder mission [7,8]. Recently, an analysis of shock shape and drag coefficient for sphere-cone geometries that unifies the two limits of sphere and sharp cone behavior was developed by Hornung et al. [9]. In this work, analytical forms for shock standoff distance as a function of only two independent variables, density ratio $\boldsymbol{\epsilon}$ and a cone angle parameter $\eta$, were confirmed through Euler simulations. Although the analysis assumes a perfect gas, the authors note that the results may be applied to reacting flows by using the average density along the stagnation streamline, as was previously done for spheres [6]. One goal of the present work was to examine this unified model for high-enthalpy $\mathrm{CO}_{2}$ flows through experiments and simulations.

For Mars missions, high-stagnation enthalpy ground test campaigns for blunt-body geometries in $\mathrm{CO}_{2}$ have been conducted in reflected shock tunnel facilities, such as the Large Energy National Shock Tunnel (LENS) I at CUBRC [10], T3 at the Australian National University [11], and T5 at the California Institute of Technology [12], as well as in expansion tube/tunnel facilities, such as LENS X at CUBRC [13], the Hypervelocity Expansion Tube at Caltech [14], and LENS XX at CUBRC [15]. The secondary acceleration of the test gas differs between the two types of facilities. In a reflected shock tunnel, the test gas is stagnated behind the reflected shock in the reservoir at high temperature and pressure leading to dissociation. When the gas is then rapidly accelerated through a large-area ratio nozzle, thermal and chemical freezing commonly occur just downstream of the throat, resulting in potential uncertainty in the freestream gas temperatures and composition at the nozzle exit. In an expansion tube, the secondary acceleration of the test gas after the primary shock occurs via an unsteady expansion wave. Expansion tube operation avoids gas stagnation and possible subsequent freezing of the thermochemical processes in a nozzle, although nonequilibrium through the unsteady expansion may need to be considered for conditions with very rapid expansion after strong shock compression.

A series of interferometric images of the shock layer in $\mathrm{CO}_{2}$ flows at a stagnation enthalpy of $9 \mathrm{MJ} / \mathrm{kg}$ over circular and elliptical cylinders were obtained in the T3 free-piston shock tunnel [11]. Additionally, interferometric images over spheres at stagnation enthalpies of
4-12 $\mathrm{MJ} / \mathrm{kg}$ in carbon dioxide flows and $10-22 \mathrm{MJ} / \mathrm{kg}$ in air and nitrogen flows were obtained in T5 [6,12]. Comparisons from T3 showed good agreement with computations using the 1991 Park et al. chemical kinetic rates with the Landau-Teller harmonic oscillator vibrational model [16].

More recently, a significant discrepancy (a factor of 2.25) between the experimentally and numerically measured shock standoff distances was observed for a Mars Science Laboratory (MSL) heatshield scaled model (70 deg sphere-cone) at an enthalpy of $5.6 \mathrm{MJ} / \mathrm{kg}$ in the LENS I reflected shock tunnel facility (Run 8) and the corresponding DPLR simulation [10]. The authors' analysis found that approximately $42 \%$ of the total enthalpy would need to be frozen in vibrational energy modes to match the predicted shock shape. They postulated that previous experiments in T5 did not show obvious evidence of thermal nonequilibrium due to a lower freestream Mach number (4.2 vs 5.7) of flow that is less expanded in the nozzle [10]. The sphere-cone tests previously carried out in the T5 facility [12] used a nozzle with a geometric area ratio of 100:1, whereas the LENS I D-nozzle had a geometric nozzle area of nearly 1000:1 [10]. This discrepancy motivated the use of different nozzle area ratios in the $\mathrm{T} 5$ facility in the present study.

Doraiswamy et al. looked to address the issue of increased shock standoff distance observed in the LENS I facility by using a statespecific vibrational model for the first few vibrational states for the species considered in their nozzle simulation and comparing to the Park two-temperature (2-T) model [17] with the Landau-Teller model for vibrational relaxation [18]. The shock standoff distance discrepancy could not be explained. Furthermore, all of the models investigated predicted that the flow is close to thermal equilibrium in the test section. The shock standoff distance was reduced as the freestream composition was predicted to be closer to chemical equilibrium.

Comparisons of shock shape measurements over sphere-cone and sphere geometries in the HET with US3D simulations carried out previously resulted in sphere standoff distances agreeing to within 7\% [14]. Perfect gas predictions of the HET freestream were used, although the equilibrium and perfect gas freestream predictions for the RC5 test condition used in that study do not differ significantly. The RC5, $h_{0}=5.6 \mathrm{MJ} / \mathrm{kg}$, test condition was chosen to achieve a first-order matching in velocity, but not Mach number, with the expansion tube experiments of CUBRC LENS X [13]. Comparisons of shock shape at an angle of attack from schlieren images obtained in experiments in the two expansion facilities also yielded very good agreement.

A compilation of shock standoff ground test data for geometries in different facilities at zero angle of attack was made by Hollis and Prabhu [19]. Comparisons with LAURA simulations with a fivereaction chemistry model and the Park 2-T model [17] for $\mathrm{CO}_{2}, \mathrm{CO}$, $\mathrm{O}_{2}, \mathrm{O}$, and $\mathrm{C}$ showed both over- and under-prediction of the experimental values obtained in four different impulse facilities, including the two used in the current study. No systematic source of this discrepancy was identified across data from all facilities. A subsequent comparison of LAURA simulations, using the Johnston and Brandis kinetic mechanism [20], with data from the LENS XX expansion tube facility found good agreement at an angle of attack [21]. In the present work, new experiments are carried out in both the T5 reflected shock tunnel and the HET. The two facilities use different gas acceleration methods to achieve a range of complementary conditions such that the facility independence of the results can be examined. Seven test conditions are chosen to span the binary-scaling and freestream conditions of the anomalous LENS I Run 8 test in addition to using conical and contour nozzles with different area ratios. The range of stagnation enthalpies and binary-scaling parameters considered are shown in Fig. 1. For comparison to flight missions, parameters for the ballistic entry 2019 ExoMars mission and lifting entry 2012 MSL mission are also included [22,23].

High-enthalpy experiments and simulations are first compared to the well-established scaling for spheres. The recent perfect gas analytical expressions from Hornung et al. [9] for sphericallyblunted cone flows are tested against reacting $\mathrm{CO}_{2}$ flow simulations using the LAURA code from NASA Langley Research Center [24]. 


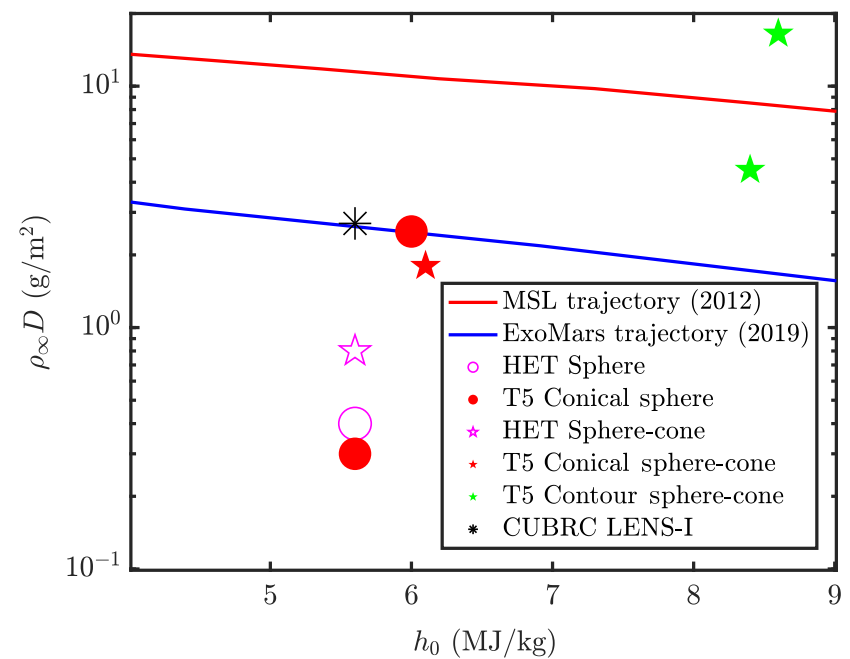

Fig. 1 Binary-scaling parameter $\rho_{\infty} D$ and stagnation enthalpy $h_{0}$ for test conditions analyzed in the present study together with values for portions of the ExoMars and MSL trajectories.

Independently, experimental data for high-enthalpy $\mathrm{CO}_{2}$ flows are also compared to these analytical expressions. Numerically calculated density profiles along the stagnation streamline are interpreted using a 1-D analysis to evaluate the contributions to the density profile (and the standoff distance) due to thermal and chemical nonequilibrium, velocity changes, and the presence of the boundary layer. Three different thermochemical models are examined: the Johnston and Brandis mechanism implemented in LAURA in 2014 [20], Cruden et al. recommended in 2018 for freestream velocities below $6.6 \mathrm{~km} / \mathrm{s}$ [25], and the Fridman 2008 mechanism that was derived in the context of a 2-T model for $\mathrm{CO}_{2}$ decomposition in plasma [26] .

\section{Experimental and Numerical Setups}

\section{A. Hypervelocity Facilities}

\section{T5 Reflected Shock Tunnel}

The T5 reflected shock tunnel uses a free piston to compress adiabatically a mixture of monatomic driver gases to high pressure (up to $120 \mathrm{MPa}$ ) and temperature (up to $4000 \mathrm{~K}$ ). The rupture of a steel diaphragm creates a primary shock wave that propagates through a $90-\mathrm{mm}$-diam shock tube containing the test gas [27]. The shock then reflects at the end wall of the reservoir where the test gas is stagnated before being accelerated through a converging-diverging nozzle. Test times are typically 1-2 ms, terminated by driver gas contamination. Two nozzles, a contoured and a conical nozzle each with an exit diameter of $300 \mathrm{~mm}$, are used in the present study. The contoured nozzle area ratio is $100: 1$, and the conical nozzle has throat inserts with area ratios of 100:1 and 900:1.

The stagnation reservoir conditions are calculated assuming thermal and chemical equilibrium behind the primary and reflected shocks using the thermodynamic routines in the Shock and Detonation Toolbox $[28,29]$. The calculated reservoir conditions for the 900:1 expansion closely match the LENS I Run 8 condition (Table 1).

The $\bar{T} 5$ nozzle flow was simulated using an axisymmetric NavierStokes solver developed by Prof. Graham Candler at the University of Minnesota to obtain the freestream conditions [30]. The vibrational energy relaxation model of Camac [31] and a five-species, sixreaction chemical mechanism is implemented [32]. A simulation was performed for each test using the experimentally measured reservoir pressure and shock velocity. A more detailed description of the method used to obtain the freestream conditions in T5 can be found in Leibowitz and Austin [33] and Leibowitz [34]. Experiments were conducted with a contoured nozzle that produces nominally uniform flow at the exit plane as well as a conical nozzle that produces diverging flow at the exit plane.
Table 1 Reservoir conditions for T52892 and CUBRC LENS I Run 8 [무]

\begin{tabular}{lcc}
\hline \hline & \multicolumn{2}{c}{ Facilities } \\
\cline { 2 - 3 } & T5 & LENS I \\
\hline Shot no. & 2892 & Run 8 \\
$\rho, \mathrm{kg} / \mathrm{m}^{3}$ & 42.7 & 38.3 \\
$T, \mathrm{~K}$ & 3623 & 3499 \\
$P, \mathrm{MPa}$ & 33.3 & 29.5 \\
$h_{0}, \mathrm{MJ} / \mathrm{kg}$ & 6.05 & 5.63 \\
$Y_{\mathrm{CO}_{2}}$ & 0.736 & 0.780 \\
$Y_{\mathrm{CO}}$ & 0.168 & 0.146 \\
$Y_{\mathrm{O}_{2}}$ & 0.091 & 0.080 \\
$Y_{\mathrm{O}}$ & 0.005 & 0.037 \\
\hline \hline
\end{tabular}

\section{Conical Nozzle Correction}

Flow divergence created by a conical nozzle geometry can result in observable differences in the flow over a model when compared to parallel flow. Recently, Hornung applied conservation of mass to diverging hypervelocity blunt-body flow over a blunt body [35]. The same analysis was applied to parallel flow except the outward radial velocity through the control volume is at the angle $\cos (\phi-\sigma)$ instead of $\cos (\phi)$, where $\phi$ is the shock angle and $\sigma$ is the angle of streamline divergence, as shown in Fig. 2. Hornung derived that the standoff distance in conical flow $\Delta_{c}$ is given by

$$
\frac{\Delta_{c}}{R_{s}}=\frac{1}{2} \frac{\rho_{\infty}}{\bar{\rho}} \frac{1}{1+\left(R_{s} / L_{0}\right)}
$$

where $L_{0}$ is the distance from virtual flow origin to the shock, and $R_{s}$ is the radius of curvature of the shock. The divergence of the conical incoming flow reduces the shock standoff distance by a factor that approaches unity as $L_{0}$ approaches infinity. $R_{s}$ is found by fitting a circle to the experimental or numerical shock shape, as suggested in Ref. [35]. Hornung verified this correction factor using a series of Euler simulations [36] for flow over a sphere, where the radii of curvature of the shock in parallel and conical flows are approximately the same, $R_{s, p} \approx R_{s, c}=R_{s}$.

However, this approximation does not generally hold for geometries such as sphere-cones, where the shock curvature difference between parallel and conical flows is discernible, as shown in Fig. 3a. We denote the shock radius in Eq. (3) as $R_{s, c}$ for conical flow and in Eq. (1) as $R_{s, p}$, and with $L=1 / \overline{2}$ for consistency, such that the standoff distance correction factor from conical to parallel flow for sphere-cone shocks can be expressed as

$$
\frac{\Delta_{p}}{\Delta_{c}}=\frac{R_{s, p}}{R_{s, c}}\left(1+\frac{R_{s, c}}{L_{0}}\right)
$$

Using a series of Euler simulations completed using AMRITA [36], this model is validated for sphere-cones using perfect gas flows of nondimensional diameters 10,15 , and 20 with a 15 deg half-angle conical nozzle, $L_{0}=1.3 \mathrm{~m}, \gamma=1.4$, and freestream Mach number of $M_{\infty}=8.9 . \pm$ The results of the Euler simulations are shown

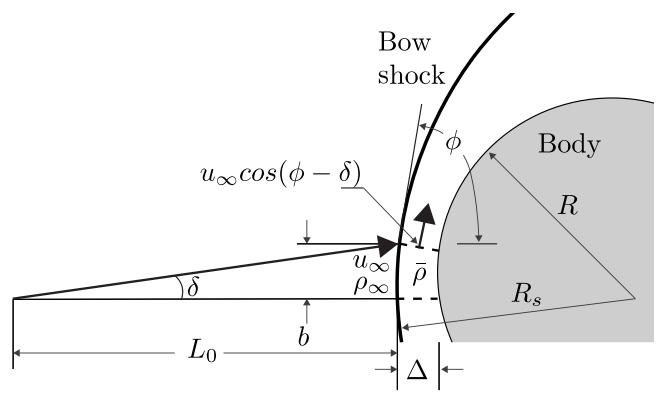

Fig. 2 Control volume analysis of conical hypervelocity flow over a blunt body. (Adapted from Hornung [35].) 


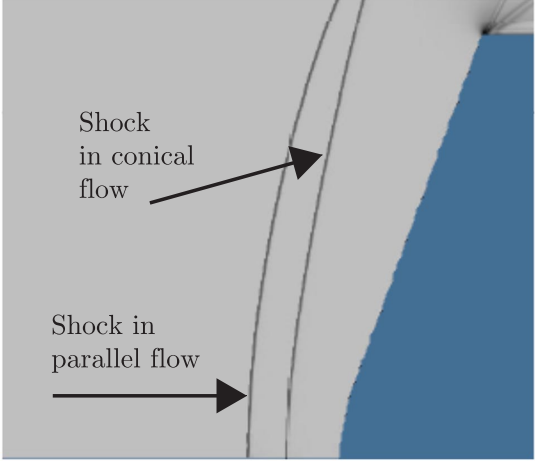

a)

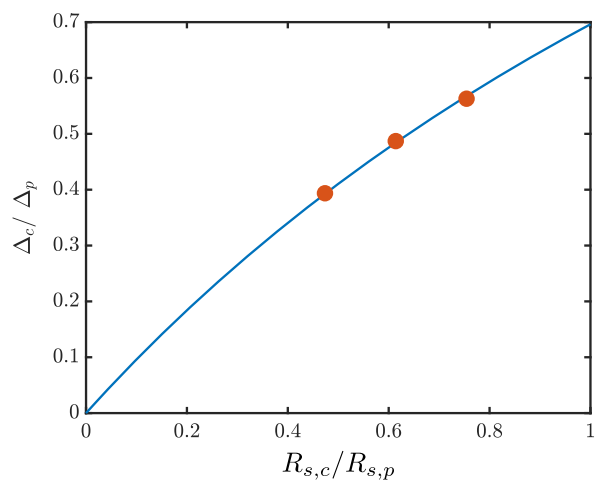

b)

Fig. 3 Simulation results of conical vs parallel freestream flow on the shock layer over sphere-cone geometries: a) an overlay of parallel and conical flow shock shape and b) comparison of model correction for shock standoff distance with selected Euler simulations.

in red circles and compared to the theoretical prediction of Eq. (ㄱ) (Fig. 3b).

The T5 conical nozzle has a 7 deg half-angle and throat inserts of various lengths to adjust the area ratio. The resulting 900:1 and 100:1 area nozzle have virtual distances to the throat of $L_{0}=1.3 \mathrm{~m}$ and $L_{0}=1.2 \mathrm{~m}$, respectively. In experiments discussed in Sec. III.B, the radius of curvature was measured from the schlieren images as $R_{s, c}=$ $17.5 \pm 1.0 \mathrm{~mm}$ for the 1-in.-diam sphere model for both T52886 and T52889 resulting in a conical standoff distance correction factors of 1.013 and 1.015 for sphere experiments when compared with parallel flow simulations. For the 7 in. MSL model experiment, T52892, where the radius of curvature of the shock between parallel and conical flows changes, $R_{s, c}=110 \pm 5.0 \mathrm{~mm}$, measured from the schlieren image and $R_{s, p}=130 \pm 5.0 \mathrm{~mm}$, measured from the corresponding parallel flow simulation results in a conical standoff distance correction factor of 1.282 . These correction factors have been applied to the experimental data for conical nozzle experiments (T52886, T52889, and T52892) to compare to simulations assuming a uniform freestream. The uncertainty in shock curvature measurements was accounted for in the overall experimental uncertainty using the propagation of error formula. This correction factor was used because a numerical capability to simulate diverging flow from the nozzle over the test article was not readily available, as was also the case for previous test campaigns in $\mathrm{T} 5[\underline{12}, \underline{19}, \underline{37}]$.

\section{Hypervelocity Expansion Tube}

The HET is an expansion tube facility that is capable of stagnation enthalpies between 2 and $8 \mathrm{MJ} / \mathrm{kg}$ and Mach numbers between 3.5 and 7.1 [38]. The facility consists of three sections: a driver, a driven, and an accelerator tube, all with $150 \mathrm{~mm}$ inner diameter. The driver section is typically filled with helium up to $4 \mathrm{MPa}$ to burst an aluminum diaphragm, propagating an initial shock wave through the test gas in the driven section. The incident shock ruptures a second (0.0005 in. Mylar) diaphragm at the driven/accelerator gas interface. An unsteady expansion fan is generated and provides the secondary acceleration of the test gas to the freestream condition. Test times are on the order of 100 to $500 \mu \mathrm{s}$. The HET freestream is predicted from 1-D gas dynamic calculations assuming equilibrium thermochemistry (Table 5). The assumption of equilibrium thermochemistry in the test gas was checked by calculations using an inhouse expansion fan solver with two vibrational models of $\mathrm{CO}_{2}$ : 1) the Camac model [31], which assumes all modes of $\mathrm{CO}_{2}$ relax at the same rate, and 2) the Doraiswamy et al. model [18], which assumes the symmetric modes are in equilibrium with the transrotational temperature and the antisymmetric mode relaxes separately [18]. For both models, the vibrational temperature differed by at most $18 \mathrm{~K}$ from the translational temperature through the unsteady expansion fan [34], justifying the assumption of thermal equilibrium in the test gas. The relaxation profile in the post-shock air accelerator gas for

\footnotetext{
Personal communication with H. G. Hornung, 2019.
}

the MSL1 condition was calculated using a state-to-state model for air [39]. The simulation showed that the accelerator gas, while not fully in equilibrium, is much closer to equilibrium than to frozen conditions during the duration of accelerator gas propagation through the test section, experimentally measured by a pitot probe to be $70 \mu \mathrm{s}$.

\section{B. Numerical Simulations}

The flowfields around sphere and sphere-cone geometries are simulated using the LAURA code from NASA Langley Research Center. LAURA is a structured, multiblock computational aerothermodynamic simulation with a Navier-Stokes solver [24,40]. The wall boundary condition is specified as a fully-catalytic, isothermal cold wall at $300 \mathrm{~K}$. Simulations with supercatalytic models were carried out to confirm sphere standoff distance is insensitive to the choice of catalysis model at the experimental conditions in this work.

The three different $\mathrm{CO}_{2}$ chemical kinetic mechanisms used in this study will be referred to as the "Johnston" (Johnston and Brandis [20]), "Cruden" (Cruden et al. [25]), and "Fridman" [26] models. The Johnston and Cruden models includes five species $\left(\overline{\mathrm{CO}}_{2}, \mathrm{CO}, \mathrm{O}_{2}, \mathrm{O}\right.$, and C) and five reactions $[20,21,25]$. In the Johnston model, the three dissociation reactions are functions of the geometric average temperature $\sqrt{T T_{V}}$ [17]. The exchange reactions are functions of the translational temperature. The Cruden model rates are a function of a single temperature. The Fridman mechanism was derived for $\mathrm{CO}_{2}$ decomposition in plasma and uses four species $\left(\mathrm{CO}_{2}, \mathrm{CO}, \mathrm{O}_{2}\right.$, and $\left.\mathrm{O}\right)$ and 16 reactions [26]. The forward dissociation reactions are dependent on $T_{V}$, whereas the backward dissociation reactions are dependent on $T$. Only the $\mathrm{CO}_{2}+\mathrm{O} \rightarrow \mathrm{CO}+\mathrm{O}_{2}$ exchange reaction is a function of $\sqrt{T T_{V}}$. The reaction rate coefficients for the three models are shown in the Appendix. Cruden compared these three models to the $\mathrm{CO}_{2}$ Electric Arc Shock Tube radiation measurements, noting a difference in the time to reach equilibrium, with Fridman being the fastest and Cruden the slowest [41]. The energy exchange between the translational-rotational and vibrational-electronic modes is modeled using a Landau-Teller formulation [40] with Landau-Teller constants [24] specified for $\mathrm{O}_{2}: A_{\tau_{\nu}}=129$ [ [ and $\mathrm{CO}_{2}: \overline{A_{\tau_{\nu}}}=270.4$ [31]. The Camac $\mathrm{CO}_{2}$ model [31] assumes the four vibrational modes relax at the same rate.

Axisymmetric grids were generated for sphere and sphere-cone geometries. An example grid is shown in Fig. 4a. The final numbers of grid cells used in the wall normal and symmetry plane are chosen based on the results of a grid sensitivity study (Table 2). Grid clustering is performed using a grid stretching function described in the LAURA user's manual using the maximum recommended constant in the grid stretching function of 4.25 [24]. The extracted standoff distance for all cases agrees to within the uncertainty of the numerical shock thickness. The variation in the calculated average density is $\bar{\rho} / \rho_{\infty}=11.27 \pm 0.07$ or $0.6 \%$. The sphere grids selected for this study had 64 cells in the symmetry plane and 256 cells in the wall-normal direction. The sphere-cone grids had 32 cells in the symmetry plane and 197 cells in the wall-normal direction. The 


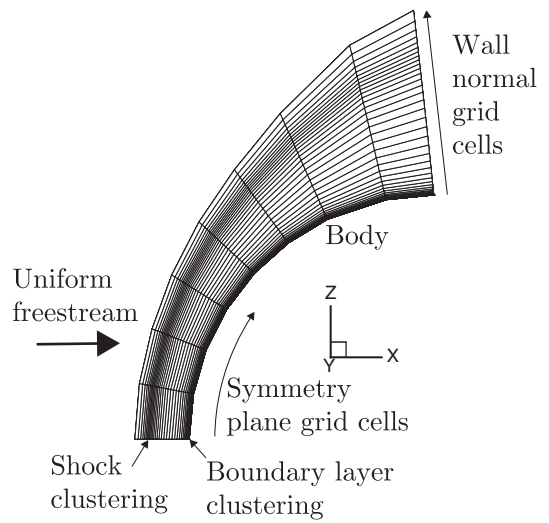

a)

Fig. 4 Setup for numerical simulations using LAURA. a) Axisymmetric sphere grid generated with 64 grid cells in the wall-normal direction and eight grid cells in the symmetry plane; b) stagnation streamline density $\rho / \rho_{\infty}$ and total enthalpy $h_{0}$ profiles for reacting, viscous, hypervelocity flow over a sphere illustrating nomenclature described in the text.

Table 2 Results of number of grid cell sensitivity study

\begin{tabular}{lcccccc}
\hline \hline & \multicolumn{7}{c}{ Cases } \\
\cline { 2 - 7 } & 1 & 2 & 3 & 4 & 5 & 6 \\
\hline $\begin{array}{l}\text { Wall-normal } \\
\text { cells }\end{array}$ & 256 & 256 & 256 & 128 & 256 & 512 \\
$\begin{array}{l}\text { Symmetry } \\
\text { plane cells }\end{array}$ & 32 & 64 & 64 & 128 & 128 & 128 \\
$\begin{array}{l}\text { Shock } \\
\text { clustering }\end{array}$ & No & No & Yes & No & No & No \\
$\begin{array}{l}\text { Standoff } \\
\text { distance, mm }\end{array}$ & 0.933 & 0.932 & 0.929 & 0.937 & 0.927 & 0.918 \\
$\begin{array}{l}\text { Uncertainty, } \\
\text { mm }\end{array}$ & \pm 0.022 & \pm 0.027 & \pm 0.012 & \pm 0.080 & \pm 0.041 & \pm 0.020 \\
$\bar{\rho} / \rho_{\infty}$ & 11.21 & 11.24 & 11.21 & 11.34 & 11.28 & 11.26 \\
\hline \hline
\end{tabular}

The inflow is the HET MSL1 perfect gas freestream condition and the geometry used is a 1-in.-diam hemisphere.

197 wall-normal cells doubled (from 97 cells) the number of cells from a grid provided by the NASA Langley Research Center Aerothermodynamics group. $\stackrel{\S}{\mathrm{s}}$ For comparisons to theoretical prediction curves, the simulation grids did not have shock clustering. For comparisons to experiments, the grids used shock clustering, which reduced the numerical shock region thickness to $2.6 \%$ of the total standoff distance (Case 3).

A comparison of the LAURA prediction with a simulation completed by Dr. Dinesh Prabhu using the NASA Ames Research Center DPLR code was made for shot T52892. The standoff distance differed by $3 \%$ (LAURA: $6.3 \mathrm{~mm}$ vs DPLR: $6.1 \mathrm{~mm}$ ). An additional DPLR simulation which incorporated a diverging freestream was carried out to test the conical nozzle correction factor over a sphere-cone model in reacting flow. The numerically predicted standoff distance was $4.5 \mathrm{~mm}$, corresponding to a correction factor of 1.355 . This agrees with the predicted correction factor of $1.282 \pm 0.073$ to within experimental uncertainty in the curvature measurement.

The theoretical predictions for shock standoff distance assume a constant radial velocity through the boundary of the control volume, which is reasonable for an inviscid shock layer. In viscous flow, there are large gradients near the wall which can be accommodated by consideration of the displacement thickness. At the Reynolds numbers of the conditions in this study, however, the displacement thickness is calculated to be an order of magnitude less than the numerical resolution. Viscous and inviscid simulations are carried out to confirm that the standoff distance is the same to within the numerical accuracy.

For comparisons with theoretical predictions, the average density along the stagnation streamline $\bar{\rho}$, normalized by the freestream density $\rho_{\infty}$, is calculated by integrating the density from the end of

\footnotetext{
${ }^{\S}$ Personal communication with B. R. Hollis, 2014.
}

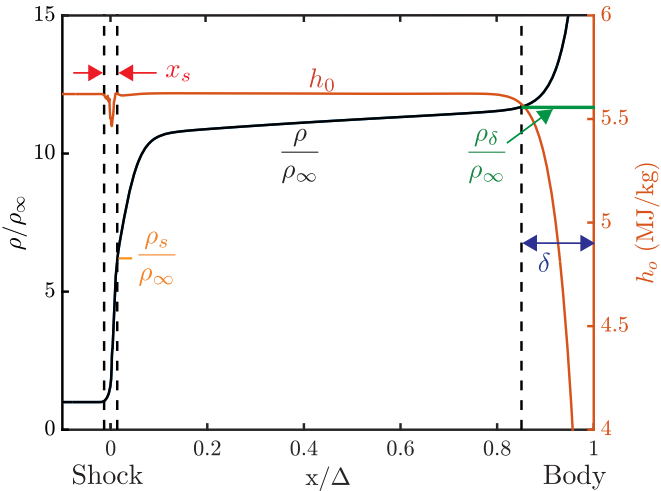

b)

the numerical shock region $x=x_{s} / 2$ to the edge of the thermal boundary layer, and assuming an inviscid density profile $\rho=\rho_{\delta}$ near the wall (Fig. 4b). The assumption of constant density will result in an underprediction of the boundary layer contribution to the average density. However, as discussed previously, the boundary layer contribution is small for the conditions considered in this work.

\section{Model Geometries and Diagnostics}

Spheres and scaled MSL 70 deg sphere-cone geometries were tested in the experiments. The models were sting mounted from the rear [34]. The flight-vehicle heat-shield base diameter was $4.5 \mathrm{~m}$ with a nose radius-to-base radius ratio of $r_{n} / R=0.5$ and a shoulder-to-base radius ratio of $r_{s} / R=0.0555$ [22]. The sphere-cone had a shoulder turning angle of $70 \mathrm{deg}$. The two sphere-cone models tested in this study were scaled with base diameters of 2 and 7 in. Only the smaller model could be used in the HET. The sphere model diameter was 1 in.

The bow-shock visualization and shock standoff distance measurement were made using schlieren in two camera configurations: highspeed videos were obtained to quantify the shock steadiness during the test time and higher-resolution single images were used to measure the shock shape, Fig. $\underline{5}$. The light source for the T5 experiments was a pulsed diode light source developed by Parziale et al. consisting of a Sony laser diode paired with a PicoLAS driver emitting light at $670 \mathrm{~nm}$ [44]. A bandpass filter and an iris placed near the focal point of the system eliminate most of the self-luminosity of the flow. A graded filter schlieren cutoff was used to avoid diffraction of the laser light. For the HET experiments, the light source was a Xenon 437B nanopulser with a knife edge for a cutoff. High-speed videos were obtained using a Shimadzu Hyper Vision HPV-X2 (256 frames with 10 bit depth and $400 \times 250$ pixel resolution) camera at a frame rate between 25,000 and 100,000 frames per second. High-resolution $(1600 \times 2400$ pixels $)$ single-shot schlieren images were obtained using a pco. 1600 camera exposed between 0.5 and $2 \mu \mathrm{s}$.

Experimental measurements of shock standoff distance at the stagnation line were extracted from each schlieren image. The shock location was defined by the peak intensity in the images, corresponding to the maximum density gradient. The body location was defined by the maximum gradient in intensity near the body. This method was used to extract standoff distance from high-speed images in Leibowitz and Austin [33].

The uncertainty reported for measurements obtained from highresolution images is the propagation of error of 1 pixel uncertainty at the body and at the shock, and when applying the conical flow correction factor, the uncertainty in determining the shock curvature. The resulting uncertainty is greater than the shot-to-shot variation for two repeat experiments at the expansion tube freestream condition and four repeats at the T52892 condition.

Standoff distance measurements were obtained for three T5 experiments as a function of test time, taken to be $0.8-1.8 \mathrm{~ms}$ after primary shock arrival at the reservoir (while the reservoir pressure 
exhibits a plateau). T52886 data are acquired at $100 \mathrm{kHz}$, and the corresponding standoff distance in test time is $9.03 \pm 0.36$ pixels $(1.24 \pm 0.05 \mathrm{~mm})$. T52889 data are acquired at $25 \mathrm{kHz}$, and the corresponding standoff distance in test time is $7.88 \pm 0.33$ pixels $(1.10 \pm 0.05 \mathrm{~mm})$. T52866 data are acquired at $25 \mathrm{kHz}$, and the corresponding standoff distance in test time is $7.56 \pm 0.61$ pixels $(1.89 \pm 0.15 \mathrm{~mm})$. One standard deviation in the standoff distance measured in the movies is taken to be the uncertainty in standoff distance for these experiments. Experimental repeat measurements were within these ranges [33].

This corresponds to standard deviations in standoff distance measured from the high-speed videos during the experimental test time of 4.0 and $4.2 \%$ for the sphere experiments, and $8 \%$ for the sphere-cone experiment [34]. These values are in reasonable agreement with a previous T5 study, which reported oscillations of shock standoff distance up to 5\% for airflows over a 7-in.-diam Apollo-shaped capsule, which were attributed to pressure fluctuations measured in the reservoir [45]. A detailed evaluation of the sensitivity of the numerical shock standoff distance to the variations in steady nozzle exit prediction due to uncertainty in experimental measurements of shock speed and reservoir pressure found up to $3.8 \%$ variation in standoff distance for the T52886, 1 in. sphere experiment [33] .

\section{Results}

A. Sphere

As discussed in the Introduction, the shock standoff distance for perfect gas or equilibrium flow over a sphere is well known to be inversely proportional to the post-shock density normalized by the freestream density. This scaling was extended to reacting flows by

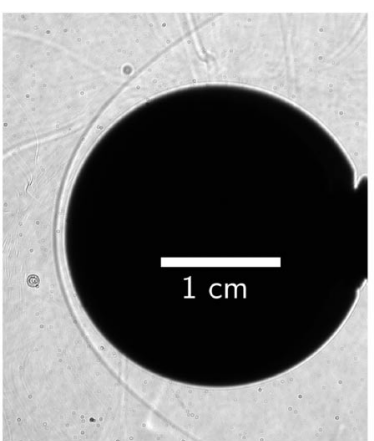

a) HET MSL1 Shot 1455

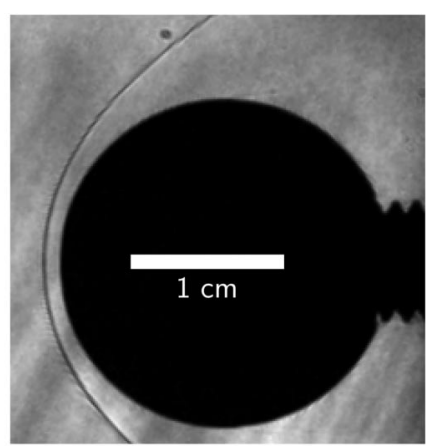

b) T5 Shot 2886
Fig. 5 Sample schlieren images for flow over $1 \mathrm{in.} \mathrm{sphere:} \mathrm{a)} \mathrm{example} \mathrm{of}$ the higher-resolution schlieren and b) extracted from high-speed movie. replacing the post-shock density by the average density along the stagnation streamline [6].

Numerical simulations of $\mathrm{CO}_{2}$ flows over spheres at three stagnation enthalpies $\left(h_{0}=5.9,9.0\right.$, and $\left.13.5 \mathrm{MJ} / \mathrm{kg}\right)$ and freestream densities ranging from 7 to $100 \mathrm{~g} / \mathrm{m}^{3}$ conditions with thermal and chemical nonequilibrium are carried out. The average density along the stagnation streamline is calculated, and the shock standoff distance is compared with the theoretical scaling (Fig. 6a). Simulations confirm the theoretical prediction for reacting $\mathrm{CO}_{2}$ flows over spherical geometries. Standoff distance is less sensitive to the binaryscaling parameter as freestream total enthalpy increases.

Experimental measurements of shock standoff distance for flows over the 1-in.-diam sphere from schlieren images obtained in the T5 and HET facilities are shown in Fig. 6b. Freestream conditions are given in Table 3. No direct measurement of the shock-layer density profile was made in these experiments, and so the data are presented as bounded by the equilibrium and chemically frozen limits in postshock density $\rho_{s}$. The upper and lower extents of the bounding boxes represent the uncertainty in the standoff distance measurement. The data from both facilities agree with the theoretical prediction to within the limits of the experimental uncertainty.

The experimental data and simulations with three different chemistry models are directly compared in Fig. 7, with the results summarized in Table $\underline{4}$. The density ratio is inverted to $\bar{\rho} / \rho_{\infty}$ so that the effects of the chemistry models on post-shock density can be observed more directly. Results are shown for the HET condition (Fig. 7a), a low-pressure T5 experiment (Fig. 7c), and a highpressure T5 experiment (Fig. 7b). All three experiments have comparable total enthalpies of $\overline{5.6}-6.0 \mathrm{MJ} / \mathrm{kg}$. The HET and T5 low-pressure experiments have comparable binary-scaling parameters $\rho_{\infty} D$ of 0.4 and $0.3 \mathrm{~g} / \mathrm{m}^{2}$, respectively. The expansion tube condition has the largest difference between chemically frozen and equilibrium post-shock density ratio limits due to the undissociated freestream. For the expansion tube condition, the simulation using the Fridman reaction mechanism is the closest match to the experimental standoff distance, but is above the upper bound of the experiment by $3 \%$. For the low-pressure T52889 condition, all three simulations are within the measured experimental uncertainty. This condition has a similar binary-scaling parameter as the expansion tube condition; however, post-shock reaction rates are slower and differences between chemical reaction models are not significant. Simulations of the higher-pressure T5 experiment with a larger binary-scaling parameter of 2.5 showed distinguishable differences in numerical standoff distance with different chemical reaction models. The numerical standoff distance using the Cruden mechanism lies within the experimental uncertainty. The Johnston
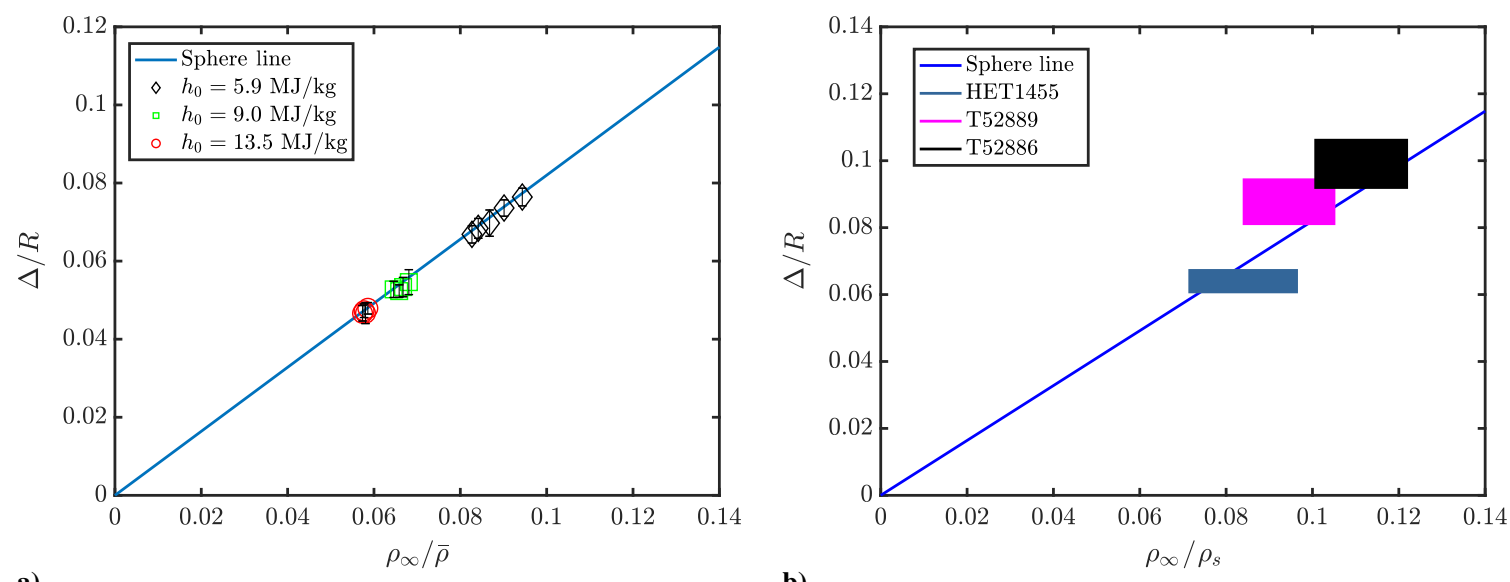

b)

Fig. 6 Comparison of a) numerical simulations and b) experimental measurements in $\mathrm{T} 5$ and HET facilities with theoretical prediction of shock standoff distance for reacting flow over a 1 -in.-diam sphere, $\Delta / R=0.82 \rho_{\infty} / \bar{\rho}$. Experimental measurements are bounded by the equilibrium (left) and chemically frozen (right) limits in post-shock density. 
Table 3 Sphere freestream conditions

\begin{tabular}{lccc}
\hline \hline & \multicolumn{3}{c}{ Facilities } \\
\cline { 2 - 4 } & HET & T5 & T5 \\
\hline Shot no. & 1455 & 2886 & 2889 \\
$D$, in. & 1.0 & 1.0 & 1.0 \\
Nozzle & No nozzle & Conical & Conical \\
Area ratio & -- & $100: 1$ & $900: 1$ \\
$\rho_{\infty} D, \mathrm{~g} / \mathrm{m}^{2}$ & 0.4 & 2.5 & 0.3 \\
$u, \mathrm{~m} / \mathrm{s}$ & 3080 & 2676 & 2840 \\
$T, \mathrm{~K}$ & 1095 & 1417 & 837 \\
$T_{V}, \mathrm{~K}$ & 1095 & 1418 & 869 \\
$P, \mathrm{kPa}$ & 3.1 & 27.5 & 1.7 \\
$\rho, \mathrm{g} / \mathrm{m}^{3}$ & 15.1 & 96.6 & 10.0 \\
$h_{0}, \mathrm{MJ} / \mathrm{kg}$ & 5.6 & 6.0 & 5.6 \\
$M a$ & 6.2 & 4.2 & 5.8 \\
$Y_{\mathrm{CO}}$ & 1.0 & 0.869 & 0.845 \\
$Y_{\mathrm{CO}}$ & 0.0 & 0.083 & 0.098 \\
$Y_{\mathrm{O}_{2}}$ & 0.0 & 0.048 & 0.056 \\
$Y_{\mathrm{O}}$ & 0.0 & $8.2 \mathrm{E}-5$ & $1.1 \mathrm{E}-6$ \\
\hline \hline
\end{tabular}

numerical standoff distance is $0.7 \%$ above the upper experimental uncertainty bound.

\section{B. Spherically Blunted Cone}

As discussed in the Introduction, flow over sphere-cone geometries exhibits a sudden transition between "sphere" and "cone" behavior corresponding to a jump in the location of the sonic line from near the sphere nose to the cone shoulder with increasing inverse density ratio $\varepsilon$. A unifying analytical expression for the shock standoff distance as a

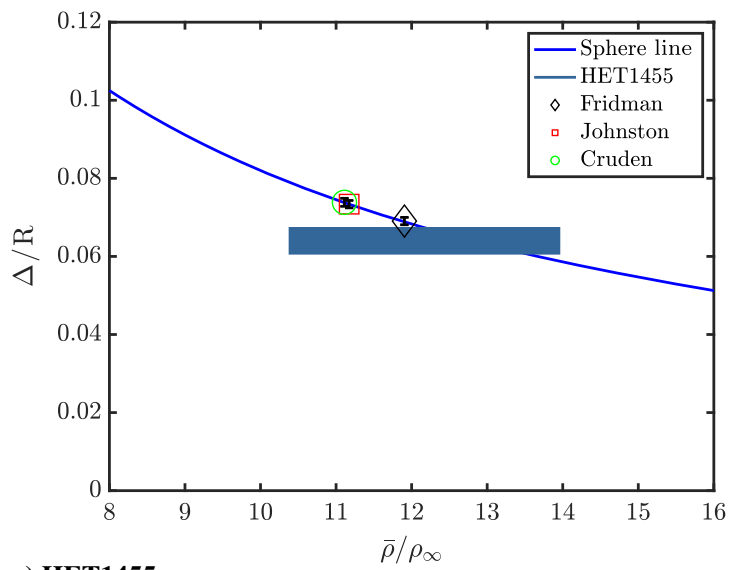

a) HET1455 function of two parameters for flow over sphere-cone geometries was recently derived by Hornung et al. [9] in the form of

$$
\frac{\Delta}{R}=g(\epsilon) f(\eta)
$$

where $R$ is the sphere-cone body radius, $\epsilon$ is the inverse shock density ratio, and $\eta$ is a function of the half-angle of the cone $\theta$ and the shock detachment angle $\theta_{d}$

$$
\begin{gathered}
\theta_{d}=2 \arctan \left(\sqrt{\frac{2}{\epsilon}}\right)-\frac{\pi}{2} \\
\eta=\frac{\theta-\theta_{d}}{\pi / 2-\theta_{d}}
\end{gathered}
$$

The respective functions $g(\epsilon)$ and $f(\eta)$ are given by

$$
\begin{gathered}
g(\epsilon)=\sqrt{\epsilon}\left(1+\frac{\epsilon}{2}\right) \\
f(\eta)=1.15(\eta-0.075)+0.06(\eta-0.075)^{2}
\end{gathered}
$$

The prediction was validated against perfect gas Euler simulations The authors postulate the scaling will also apply to reacting flows if the average density along the stagnation streamline replaces the postshock density, as was the case for spheres.

We perform reacting Navier-Stokes simulations under conditions of thermal and chemical nonequilibrium using LAURA. Shock standoff distances and average density profiles are extracted from

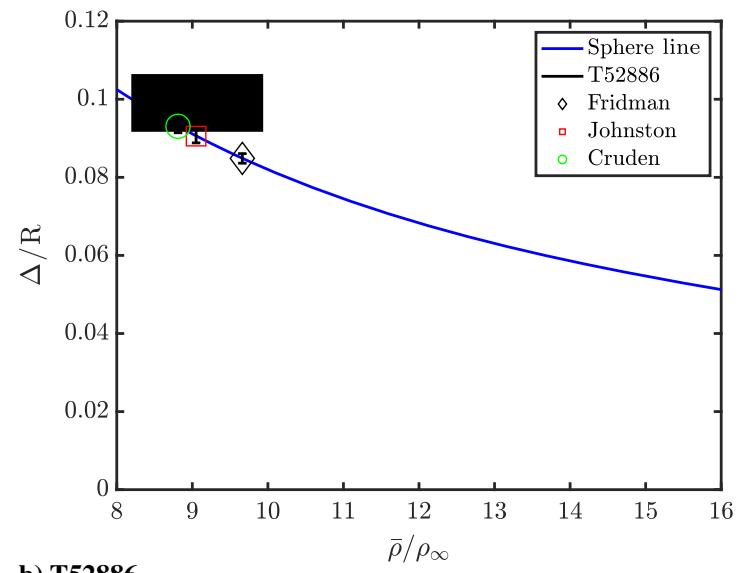

b) $\mathbf{T 5 2 8 8 6}$

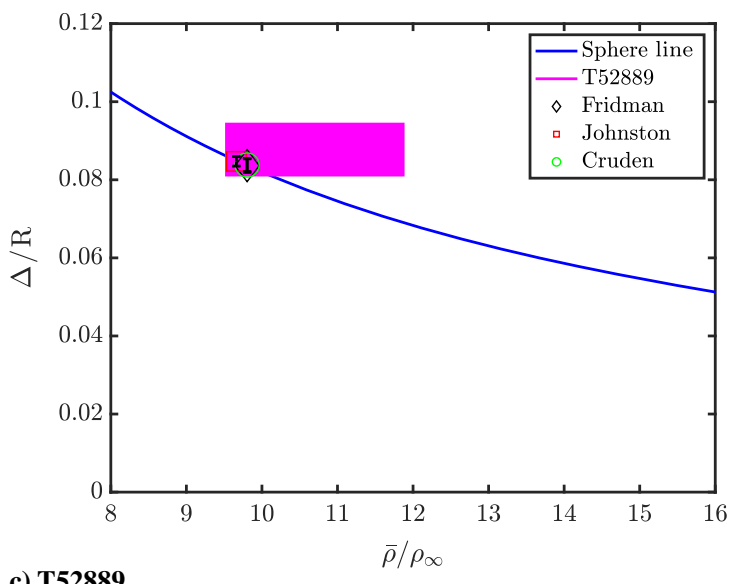

c) $\mathbf{T 5 2 8 8 9}$ 
Table 4 Sphere experimental and numerical standoff distances and density ratios

\begin{tabular}{llccc}
\hline \hline & & \multicolumn{3}{c}{ Shot no. } \\
\cline { 3 - 5 } & & HET1455 & T52889 & T52886 \\
\hline$\Delta / R$ & Experiment & 0.064 & 0.087 & 0.098 \\
& Uncertainty & \pm 0.003 & \pm 0.007 & \pm 0.006 \\
& Cruden & 0.074 & 0.084 & 0.093 \\
& Johnston & 0.073 & 0.084 & 0.091 \\
& Fridman & 0.069 & 0.082 & 0.085 \\
\hline $\bar{\rho} / \rho_{\infty}$ & Chemically frozen & 10.4 & 9.5 & 8.2 \\
& Cruden & 11.0 & 9.7 & 8.6 \\
& Johnston & 11.2 & 9.7 & 9.2 \\
& Fridman & 11.9 & 10.0 & 9.8 \\
& Equilibrium & 14.1 & 11.9 & 9.9 \\
& Closest model(s) & Fridman & Johnston and Cruden & All three \\
\hline
\end{tabular}

the simulations and compared with the analytical expression from Hornung et al. [9] (Fig. 8a). The curve chosen for comparison from Hornung et al. is the result for no shoulder radius $\left(r_{s} / R=0\right)$. The transition from sphere to cone behavior is very well captured by the simulations, validating the use of the Hornung et al. model for reacting $\mathrm{CO}_{2}$ flows over sphere-cones.

Experiments are performed in both the T5 and HET facilities. The predicted freestream conditions for the five sphere-cone experiments analyzed in this study are shown in Table 5. Example schlieren images are presented in Fig. 9. Experimentally measured shock standoff distances are compared with the analytical predictions of Hornung et al. [9] in Fig. 8b. As the shock-layer density profile was not measured independently in the experiments, the boxes again represent limits given by the frozen (left) and equilibrium (right) post-shock values. The upper and lower bounds represent the experimental uncertainty in the standoff distance measurement. The CUBRC LENS I Run 8 data point is also included.

As with the sphere experiments, experimental results are in good agreement with the theoretical prediction, with the exception of the CUBRC LENS I data point, shown in green. MacLean and Holden's analysis of LENS I Run 8 found that $42 \%$ of the total enthalpy of the flow would need to be frozen in their simulations to match the measured CUBRC shock shape [10]. The T5 and HET data span the binaryscaling parameter of LENS I, with the 900:1 nozzle experiment (T52892; pink box) as the closest match to the experimental condition.

The sphere-cone experiments and simulations with three different kinetic mechanisms are directly compared in Fig. 10 and Table $\underline{6}$. As with the sphere comparisons, the density ratio is inverted to $\bar{\rho} / \bar{\rho}_{\infty}$ so that the effects of the chemistry models on post-shock density can be interpreted more directly. The two conditions at similar enthalpies
Table 5 Freestream conditions for the sphere-cone tests

\begin{tabular}{lccccc}
\hline \hline & \multicolumn{5}{c}{ Facilities } \\
\cline { 2 - 6 } & HET & T5 & T5 & T5 & LENS I \\
\hline Shot no. & MSL1-1467 & 2866 & 2902 & 2892 & Run 8 \\
MSL $D$, in. & 2.0 & 2.0 & 7.0 & 7.0 & 12.0 \\
Nozzle & No nozzle & Contour & Contour & Conical & D-nozzle \\
Area ratio & -- & $100: 1$ & $100: 1$ & $900: 1$ & $1000: 1$ \\
$\rho_{\infty} D, \mathrm{~g} / \mathrm{m}^{2}$ & 0.8 & 4.5 & 16.5 & 1.8 & 2.7 \\
$u, \mathrm{~m} / \mathrm{s}$ & 3080 & 3123 & 3160 & 2937 & 2871 \\
$T, \mathrm{~K}$ & 1095 & 1751 & 1793 & 855 & 892 \\
$T_{V}, \mathrm{~K}$ & 1095 & 1752 & 1793 & 887 & 896 \\
$P, \mathrm{kPa}$ & 3.1 & 33.3 & 35.9 & 1.5 & 1.6 \\
$\rho, \mathrm{g} / \mathrm{m}^{3}$ & 15.1 & 88.3 & 92.7 & 8.8 & 9.0 \\
$h_{0}, \mathrm{MJ} / \mathrm{kg}$ & 5.6 & 8.4 & 8.6 & 6.1 & 5.6 \\
$M a$ & 6.2 & 4.3 & 4.3 & 5.9 & 5.7 \\
$Y_{\mathrm{CO}}$ & 1.000 & 0.728 & 0.719 & 0.828 & 0.863 \\
$Y_{\mathrm{CO}}$ & 0.000 & 0.173 & 0.179 & 0.110 & 0.087 \\
$Y_{\mathrm{O}_{2}}$ & 0.000 & 0.097 & 0.100 & 0.062 & 0.050 \\
$Y_{\mathrm{O}}$ & 0.000 & 0.002 & 0.002 & $2.0 \mathrm{E}-5$ & $0.0 \mathrm{E}-5$ \\
\hline \hline
\end{tabular}

(5.6-6.1 MJ/kg) to the LENS I Run 8 condition are the HET1467 2 in. MSL experiment (Fig. 10a) and the T52892 7 in. MSL experiment (Fig. 10b). For the expansion tube sphere-cone experiment HET $1 \overline{467}$, the simulation using the Fridman rates is the closest match to the experimental standoff distance, as was the case for flow over a sphere. The numerical standoff distance is up to $11 \%$ greater than the upper bound of the experimental measurement. In the T52892 experiment, the 7 in. sphere-cone experimental measurement is corrected using a factor of 1.282 for conical flow. After correction, as for sphere experiments at the similar lower-density condition (T52889), all three simulations are within the experimental uncertainty for T52892. These results suggest that at reflected shock tunnel conditions with a lower binary-scaling parameter $\left(\rho_{\infty} D=0.3\right.$ to $\left.1.8 \mathrm{~g} / \mathrm{m}^{2}\right)$, the degree of reaction is sufficiently low that differences between the three chemical reaction models are not large enough to be discerned.

The higher-enthalpy (8.4-8.6 MJ/kg) high-density condition tested with a 2 in. sphere-cone model, T52866 (Fig. 10c), and a 7 in. sphere-cone model, T52902 (Fig. 10d), showed much greater differences between the chemical reaction models, with reasonable agreement in numerical standoff distance using the Johnston and Cruden rates, whereas numerical standoff distance using the Fridman rates is outside the experimental uncertainty at both values of the binary-scaling parameter $\left(\rho_{\infty} D=4.5\right.$ and $\left.16.5 \mathrm{~g} / \mathrm{m}^{2}\right)$.

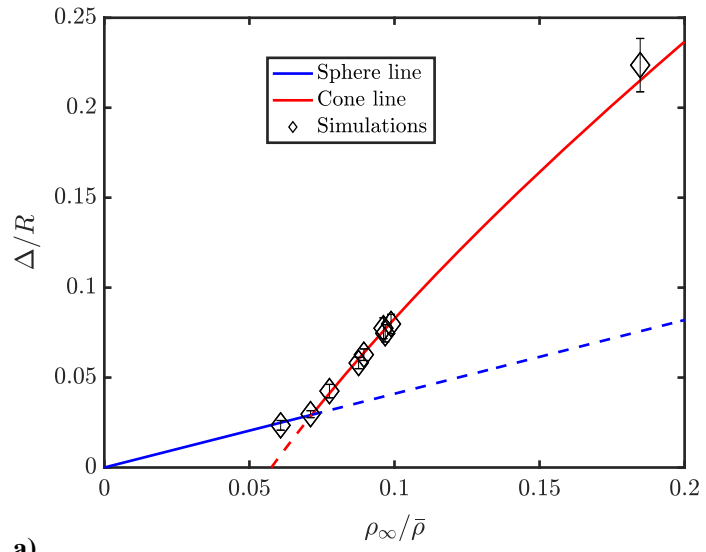

a)

Fig. 8 Comparison of sphere-cone experiments and simulations with theoretical prediction: a) reacting flow simulations with various freestream conditions, b) Experimental data bounded by equilibrium (left) and chemically frozen (right) limits in post-shock density.

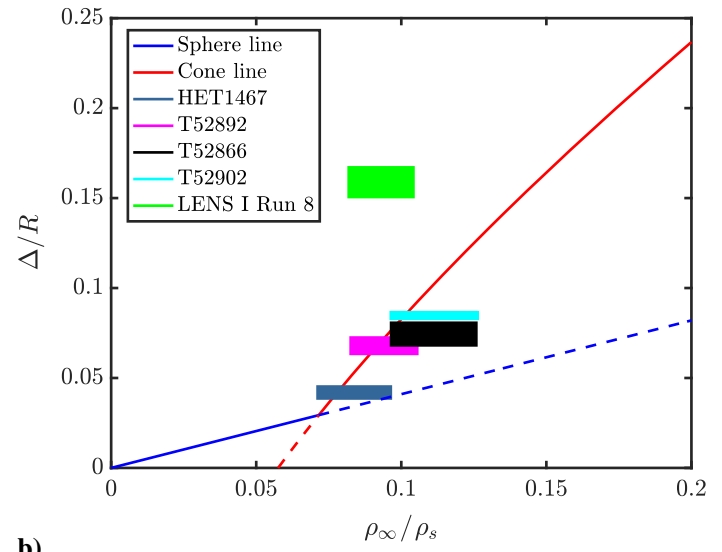

b) 


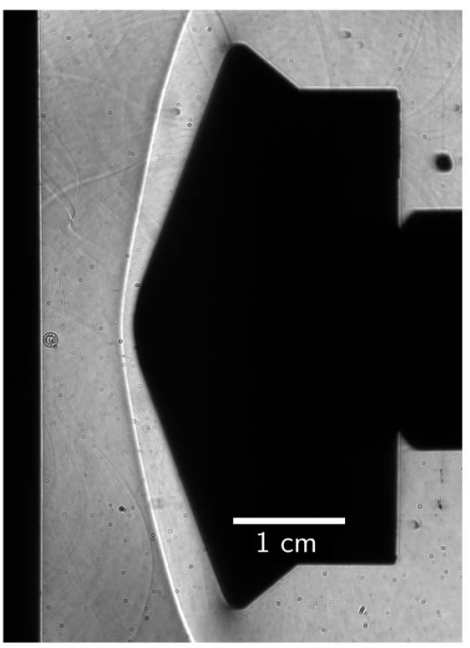

a) HET1467

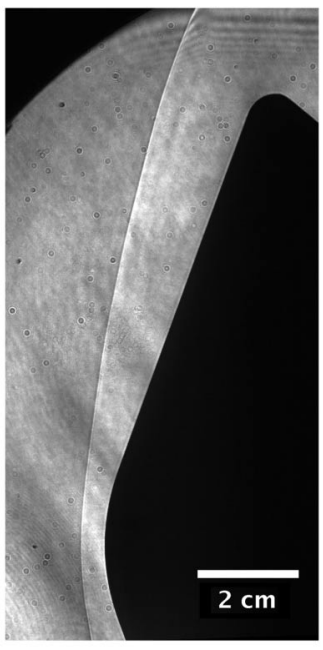

b) $\mathbf{T 5 2 8 9 2}$
Fig. 9 Sample sphere-cone schlieren images from HET and T5.

There was no evidence that vibrational freezing in the T5 nozzle significantly affects the shock standoff distance even with the 1000:1 area ratio nozzle. A possible explanation for the standoff distance discrepancy in LENS I Run 8 might be driver-gas contamination due to over-tailoring [49].

\section{Stagnation Streamline Analysis}

The motivation for the stagnation streamline analysis is to quantify the magnitude of the contribution from each nonequilibrium process to

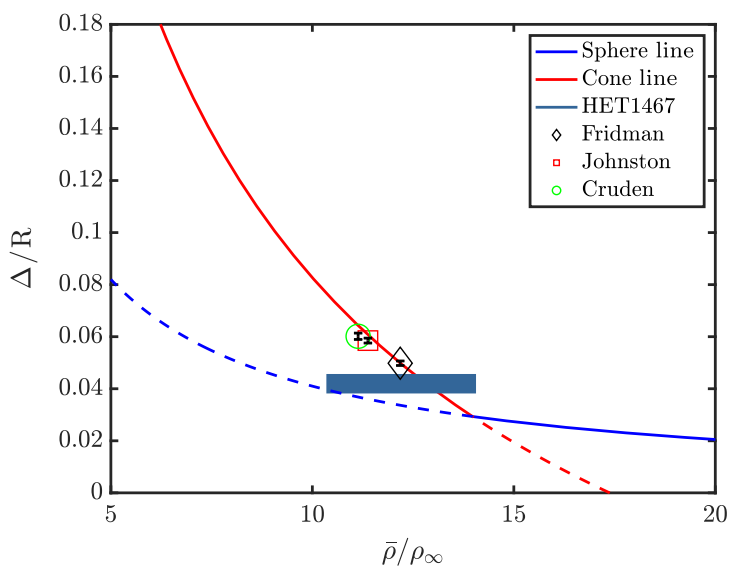

a) HET1467

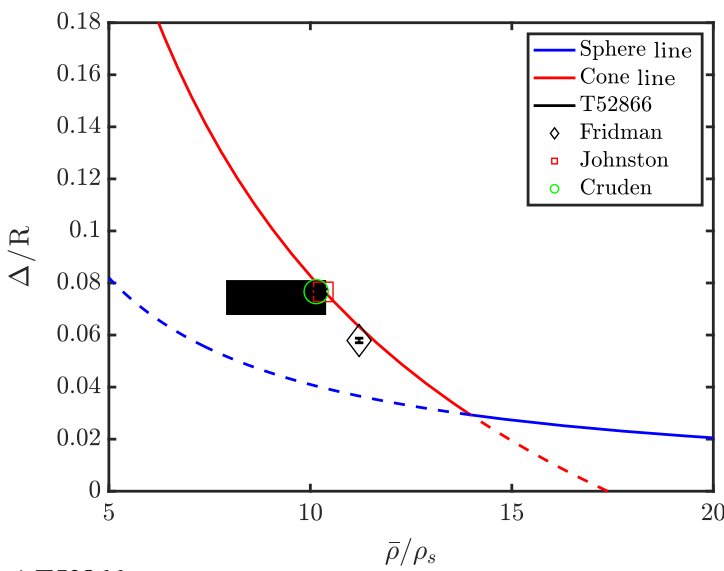

the average density, the parameter that correlates with the standoff distance. In reacting flows at the conditions of this study, the density behind a vibrationally frozen shock wave can change due to three inviscid effects: chemical nonequilibrium, vibrational nonequilibrium, and the velocity profile along the stagnation streamline. Additionally, the density can change due to viscous effects in the boundary layer. Between the shock and the boundary layer, the flow is assumed to be inviscid and adiabatic. The caloric equation of state equation can be written in the general form

$$
h=h(P, \rho, q)
$$

where $q$ is a general nonequilibrium variable [46]. Wen and Hornung considered the case of chemical nonequilibrium behind strong shock waves, where vibrational equilibrium is reached quickly and the nonequilibrium effects are given by the chemical composition change, $q=Y_{i}$, the species mass fraction [6]. Houwing et al. [47] followed this analysis for ballistic range experiments, where composition is frozen and vibrational nonequilibrium dominates with $q=e_{V}$, the vibrational energy. In high-enthalpy hypervelocity experiments at relatively low densities, both chemical and vibrational nonequilibrium can occur simultaneously, and the equations of state can be written as

$$
h\left(P, \rho, Y_{i}, e_{V}\right)=\sum_{i=1}^{n} Y_{i} h_{i}^{*}+\left(e_{V}-e_{V}^{*}\right)
$$

where the superscript $*$ represents thermal equilibrium.

The change in enthalpy along the stagnation streamline can be written as

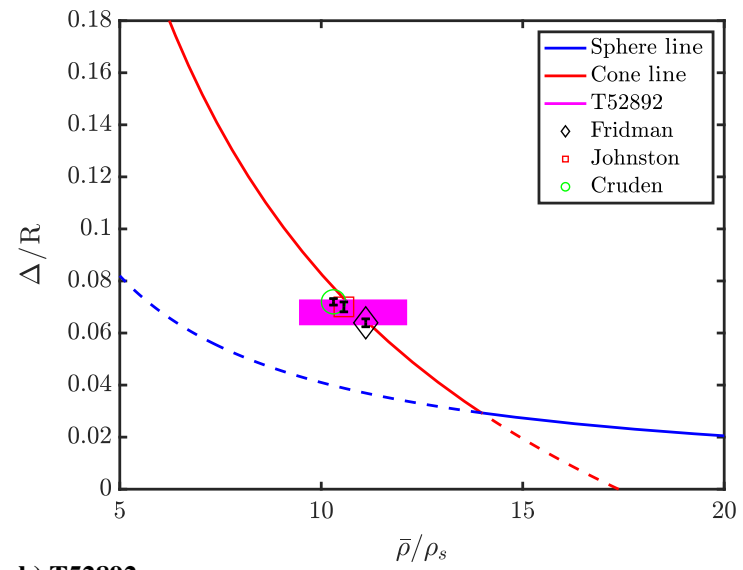

b) $\mathbf{T 5 2 8 9 2}$

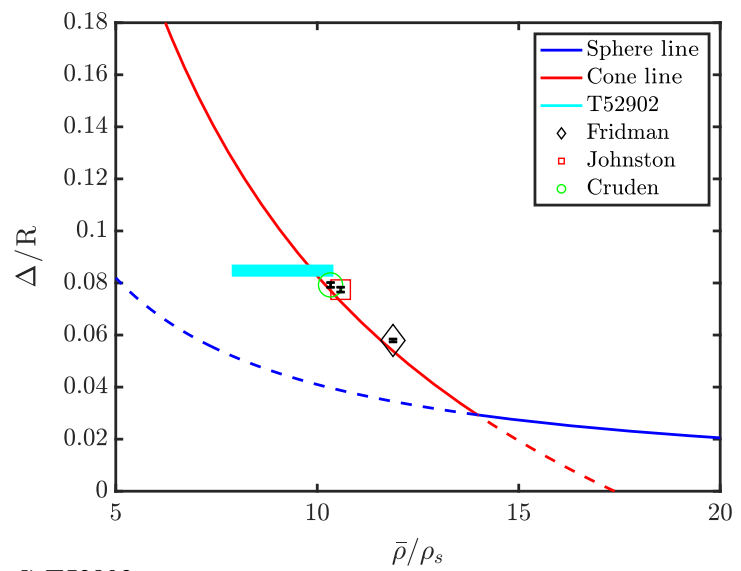

d) $\mathbf{T 5 2 9 0 2}$

Fig. 10 Comparison of sphere-cone experiments, simulations with different kinetic rates, and theoretical line; experimental data are bounded by equilibrium (right) and chemically frozen (left) limits in post-shock density. 
Table 6 Sphere-cone experimental and numerical standoff distances and density ratios

\begin{tabular}{llcccc}
\hline \hline & & \multicolumn{4}{c}{ Shot no. } \\
\cline { 3 - 6 } & & HET1476 & T52892 & T52866 & T52902 \\
\hline$\Delta / R$ & Experiment & 0.042 & 0.068 & 0.074 & 0.085 \\
& Uncertainty & \pm 0.003 & \pm 0.004 & \pm 0.006 & \pm 0.002 \\
& Cruden & 0.060 & 0.072 & 0.077 & 0.079 \\
& Johnston & 0.059 & 0.071 & 0.077 & 0.077 \\
& Fridman & 0.050 & 0.065 & 0.058 & 0.058 \\
\hline $\bar{\rho} / \rho_{\infty}$ & Chemically & 10.4 & 9.5 & 8.0 & 7.9 \\
& frozen & & & & \\
& Cruden & 11.1 & 10.3 & 10.1 & 10.3 \\
& Johnston & 11.4 & 10.6 & 10.3 & 10.6 \\
& Fridman & 12.2 & 11.1 & 11.2 & 11.9 \\
& Equilibrium & 14.0 & 12.1 & 10.3 & 10.4 \\
& Closest & Fridman & All & Johnston and & Johnston and \\
& model(s) & & three & Cruden & Cruden \\
\hline \hline
\end{tabular}

$$
\frac{d h}{d x}=\frac{d h^{*}}{d x}+\frac{d\left(e_{v}-e_{v}^{*}\right)}{d x}
$$

where $h^{*}=f\left(P, \rho, Y_{i}\right)$, and the total derivative of $h^{*}$ is defined as

$$
\frac{d h^{*}}{d x}=\frac{\partial h^{*}}{\partial P} \frac{d P}{d x}+\frac{\partial h^{*}}{\partial \rho} \frac{d \rho}{d x}+\frac{\partial h^{*}}{\partial Y_{i}} \frac{d Y_{i}}{d x}
$$

The derivatives in Eq. (11) can be evaluated using the inviscid, adiabatic flow conservation equations along a streamline for momentum

$$
\frac{d P}{d x}=-\rho u \frac{d u}{d x}
$$

and energy

$$
\frac{d h}{d x}=-u \frac{d u}{d x}
$$

the definition of the thermal equilibrium sound speed [46]

$$
\left(a^{*}\right)^{2}=\frac{-\left(\partial h^{*} / \partial \rho\right)}{\left(\partial h^{*} / \partial P\right)-1 / \rho}
$$

and the thermodynamic equation of state

$$
P=\rho \boldsymbol{R} T
$$

More details of the algebraic and substitution steps are included in Leibowitz [34]. Solving for $d \rho / d x$, the density profile along the stagnation streamline can be written in a form that identifies the contributions due to convection, chemical nonequilibrium, and vibrational nonequilibrium

$$
\begin{aligned}
\frac{d \rho}{d x}= & \rho\left[\left(-\frac{u}{\left(a^{*}\right)^{2}}\right) \frac{d u}{d x}\right]+\rho\left[\sum_{i=1}^{n}\left(-\frac{\boldsymbol{R}_{i}}{\boldsymbol{R}}+\frac{h_{i}^{*}}{C_{p}^{*} T}\right) \frac{d Y_{i}}{d x}\right] \\
& +\rho\left[\frac{1}{C_{p}^{*} T} \frac{d\left(e_{V}-e_{V}^{*}\right)}{d x}\right]
\end{aligned}
$$

The thermodynamic software Cantera and Shock and Detonation Toolbox $[28,48]$ are used to analyze the stagnation streamline density profile from full-field LAURA simulations as follows. We assume a 2-T model, where one temperature $T$ describes the distribution of heavy-particle translational and rotational energies, and that a second temperature $T_{V}$ describes the distribution of vibrational, electronic, and electron translational energies [40]. Additionally, this model assumes rotational modes are fully excited.
The mass weighted total vibrational-electronic energy is defined as

$$
e_{V}=\sum_{i=1}^{n} Y_{i} e_{V, i}
$$

The vibrational-electronic energy is defined as

$$
e_{V, i}\left(T_{V}\right)=h_{i}\left(T_{V}\right)-h_{\mathrm{tr}, i}\left(T_{V}\right)
$$

Similarly

$$
e_{V, i}^{*}(T)=h_{i}^{*}(T)-h_{\mathrm{tr}, i}(T)
$$

Equation (17) is valid for the adiabatic, inviscid portion of the shock layer. The extraction of data from simulations originates at the end of the numerical shock region $x_{s}$, defined as where the total enthalpy deviates from the freestream value of $5.6 \mathrm{MJ} / \mathrm{kg}$ by $\pm 0.05 \mathrm{MJ} / \mathrm{kg}$. The input and output to this region are listed in Table 7 for three different chemistry models. Here, the post-shock conditions, denoted by subscript $s$, are calculated at the output location of the numerical shock region. While significant vibrational excitation occurs in the numerical shock region, the chemical reactions are negligible, as evidenced by the change in mass fraction of $\mathrm{CO}_{2}$ from 1.00 to 0.98 (Cruden mechanism).

Example profiles obtained by integrating Eq. (17) for simulations of the HET1455 1-in.-diam sphere experiment with three kinetic models are shown in Fig. 11. The density profiles are similar in the convection and vibration terms, but are distinguished by differences in the chemical term.

The average density along the stagnation streamline that defines the standoff distance in viscous reacting flows can be written in terms of the individual contributions

$$
\frac{\bar{\rho}}{\rho_{\infty}}=\frac{\rho_{s}}{\rho_{\infty}}+\frac{\bar{\rho}_{d\left(e_{V}-e_{V}^{*}\right)}}{\rho_{\infty}}+\frac{\bar{\rho}_{d Y_{i}}}{\rho_{\infty}}+\frac{\bar{\rho}_{\mathrm{du}}}{\rho_{\infty}}+\frac{\bar{\rho}_{\mathrm{bl}}}{\rho_{\infty}}
$$

After the numerical shock region, the total average density $\bar{\rho}$ is composed of the post-shock density $\rho_{s}$ and the inviscid contributions average density from convection $\bar{\rho}_{\text {du }}$, average density from chemical nonequilibrium $\bar{\rho}_{d Y_{i}}$, and average density from vibrational nonequilibrium $\bar{\rho}_{d\left(e_{V}-e_{V}^{*}\right)}$, as well as the contribution from the viscous boundary-layer region $\bar{\rho}_{\mathrm{bl}}$. The three inviscid contributions $\bar{\rho}_{\mathrm{du}}, \bar{\rho}_{d Y_{i}}$, and $\bar{\rho}_{d\left(e_{V}-e_{V}^{*}\right)}$ are calculated by integrating the three respective terms on the right-hand side of Eq. (17), as shown in Fig. 11, and averaging from the end of the numerical shock region $x_{2} / 2 \overline{\text { to }}$ the edge of the boundary layer $\Delta-\delta$.

The results of this analysis for the MSL1 HET condition flow over a 1 in. sphere simulation using the Fridman, Cruden, and Johnston models, and also the Johnston model assuming one-temperature (1-T) are presented in Table 8 and Fig. 12. The numerical error $\bar{\rho}_{\text {error }}$ accumulated during this term-by-term integration is

Table 7 HET MSL1 1 in. sphere simulation conditions at the exit of the numerical shock region

\begin{tabular}{lcccccc}
\hline \hline & Freestream & $\begin{array}{c}\text { Frozen } \\
\text { shock }\end{array}$ & Fridman & Cruden & Johnston & $\begin{array}{c}\text { Johnston } \\
1-\mathrm{T}\end{array}$ \\
\hline$u_{s} / u_{\infty}$ & 1.00 & 0.19 & 0.16 & 0.15 & 0.15 & 0.10 \\
$Y_{\mathrm{CO}_{2, s}}$ & 1.000 & 1.000 & 1.000 & 0.982 & 0.999 & 0.997 \\
$T_{s}$ & 1107 & 7817 & 6825 & 6363 & 6621 & 4451 \\
$T_{V, s}$ & 1107 & 1107 & 2308 & 2439 & 2495 & $\mathrm{NA}$ \\
$\rho_{s} / \rho_{\infty}$ & 1.0 & 5.2 & 6.3 & 6.7 & 6.5 & 10.4 \\
\hline \hline
\end{tabular}

Frozen shock assumes a vibrationally frozen shock wave. A 1-T model case is also considered. NA $=$ not applicable. 


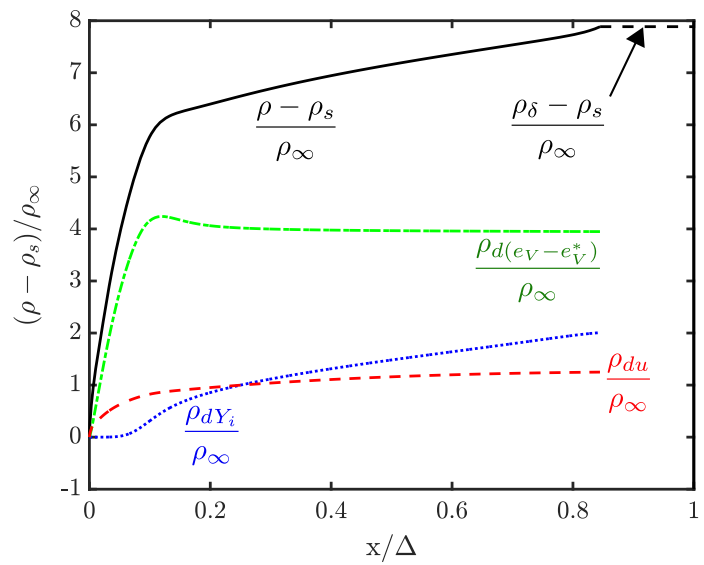

a) Fridman rates, $\Delta=0.88 \mathrm{~mm}$

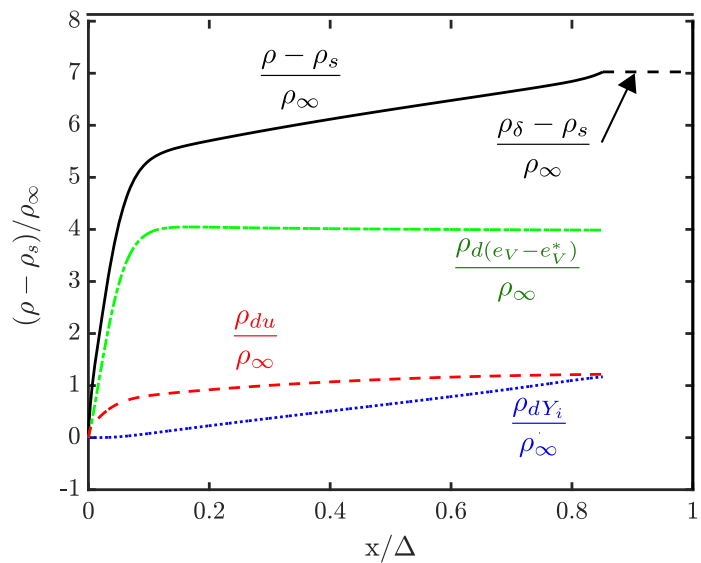

c) Johnston rates, $\Delta=0.93 \mathrm{~mm}$

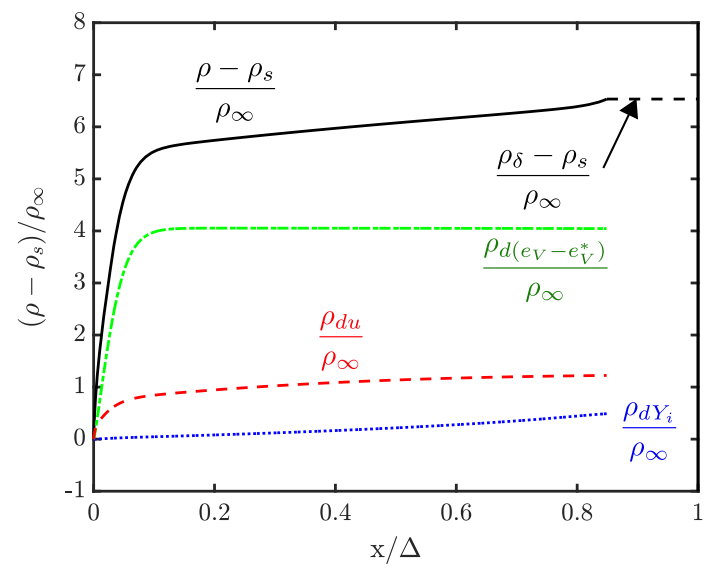

b) Cruden rates, $\Delta=0.94 \mathrm{~mm}$

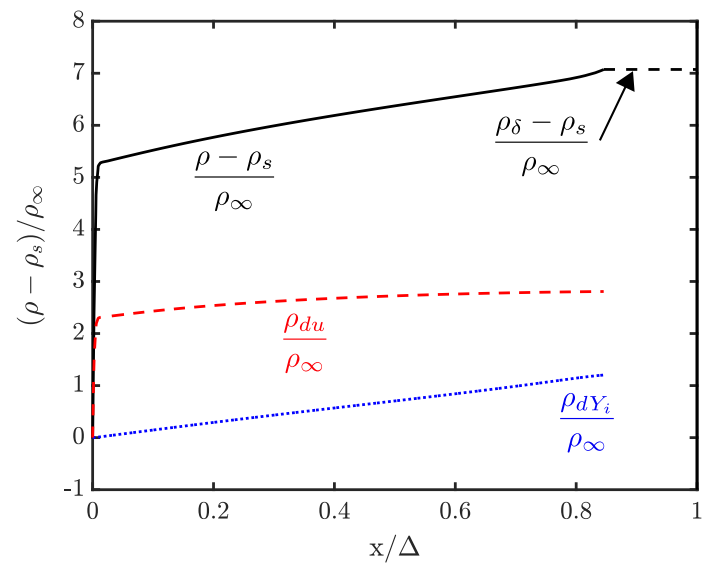

d) Johnston rates assuming $T=T v, \Delta=0.91 \mathrm{~mm}$

Fig. 11 Comparing chemistry models through rise in density due to individual contributions for HET, MSL1-1455 1-in.-diam sphere; the three inviscid contributions add up to the total density profile indicated by the solid black line; the frozen shock density ratio is $\rho_{s} / \rho_{\infty}=5.2$.

found by calculating the difference between the average density in the post-shock inviscid flow region directly extracted from the simulation and the sum of the average individual contributions. The numerical error $\bar{\rho}_{\text {error }} / \rho_{\infty}$ is at most 0.1 , or $0.9 \%$ of the total average density.

The numerical shock region density rise can be largely attributed to the vibrational excitation occurring, as shown in Table 7. The combination of the numerical shock region, vibrational nonequilibrium, and convection contributions to the total average density is within $\bar{\rho} / \rho_{\infty}=0.2$ for the three different chemistry models. The largest difference in total average density contributions between the three chemistry models is observed in the chemical nonequilibrium contribution, as shown in Fig. 13. The

Table 8 Contribution to the total density, $\bar{\rho} / \rho_{\infty}$

\begin{tabular}{|c|c|c|c|c|}
\hline Kinetic model & Fridman & Cruden & $\begin{array}{c}\text { Johnston } \\
2-\mathrm{T}\end{array}$ & $\begin{array}{c}\text { Johnston } \\
1-\mathrm{T} \\
\end{array}$ \\
\hline Frozen jump & 5.2 & 5.2 & 5.2 & 10.4 \\
\hline Numerical shock region & 1.1 & 1.5 & 1.3 & 0.0 \\
\hline $\begin{array}{l}\text { Vibrational } \\
\text { nonequilibrium }\end{array}$ & 3.5 & 3.3 & 3.3 & 0.0 \\
\hline Convection & 0.8 & 0.7 & 0.7 & 0.3 \\
\hline Chemical nonequilibrium & 1.2 & 0.2 & 0.6 & 0.6 \\
\hline Boundary layer & 0.1 & 0.1 & 0.1 & 0.1 \\
\hline Numerical error & 0.1 & 0.1 & 0.1 & 0.0 \\
\hline Total & 12.0 & 11.1 & 11.3 & 11.4 \\
\hline$\Delta / R$ (simulation) & 0.0691 & 0.0738 & 0.0734 & 0.0717 \\
\hline
\end{tabular}

simulations using the Cruden et al. [25] chemistry model result in a chemical nonequilibrium contribution of $\bar{\rho} / \rho_{\infty}=0.2$ compared to an increase of $\bar{\rho} / \rho_{\infty}=1.2$ from simulations using the Fridman chemistry model. The chemical nonequilibrium contribution from the Johnston chemistry model is closer to the contribution from the Cruden model with an increase of $\bar{\rho} / \rho_{\infty}=0.6$.

The contributions are consistent with the difference in standoff distance predicted by the different chemistry models, with 0.5 and $6.4 \%$ decreases in standoff distance extracted from the simulation using the Cruden mechanism compared to the standoff distance extracted from the simulation using the Fridman and Johnston mechanisms, respectively. The average density extracted from the Johnston mechanism using the 2-T model and 1-T model resulted in a difference of $\bar{\rho} / \rho_{\infty}=0.1$. The standoff distance from the simulation decreases by $2.3 \%$ when the Johnston $1-\mathrm{T}$ model is used instead of the Johnston 2-T chemistry model.

Directly behind the shock wave, the density rise in simulations using the Fridman chemical reaction model occurs over a longer distance compared to the density rise in simulations with the Johnston and Cruden models, because the Fridman dissociation reaction rates are controlled by the vibrational temperature. Once thermal equilibrium is reached, the Fridman model predicts the density profile reaches chemical equilibrium in a shorter distance than the Johnston and Cruden models. The overall nondimensional density increases due to chemistry $\bar{\rho}_{d Y_{i}} / \rho_{\infty}$ are $0.49,1.17$, and 2.00 from simulations using the Cruden, Johnston, and Fridman models, respectively. Based on this analysis, the Fridman kinetic mechanism appears to be the most appropriate for the HET MSL1 condition. 


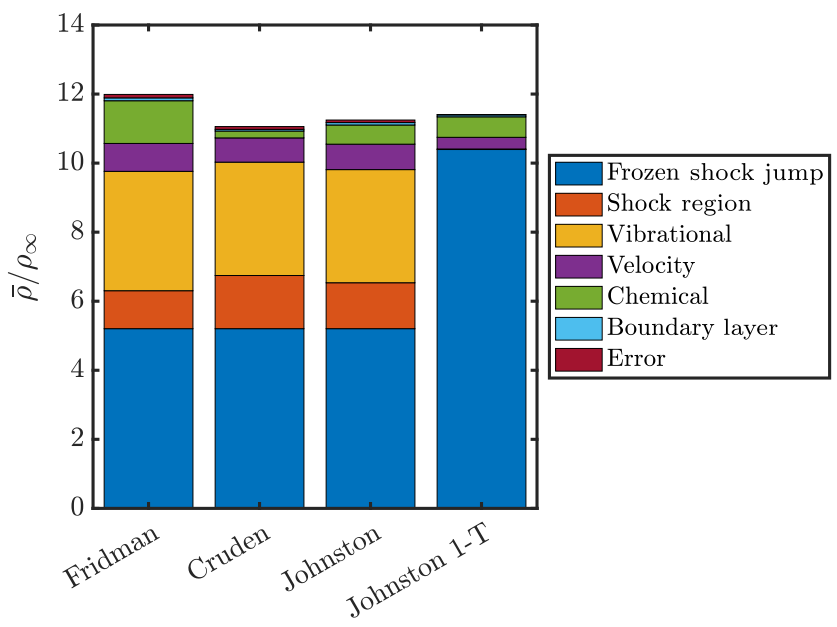

Fig. 12 Contributions to the total density profile due to component terms for HET MSL1 test condition flow over a 1-in.-diam sphere.

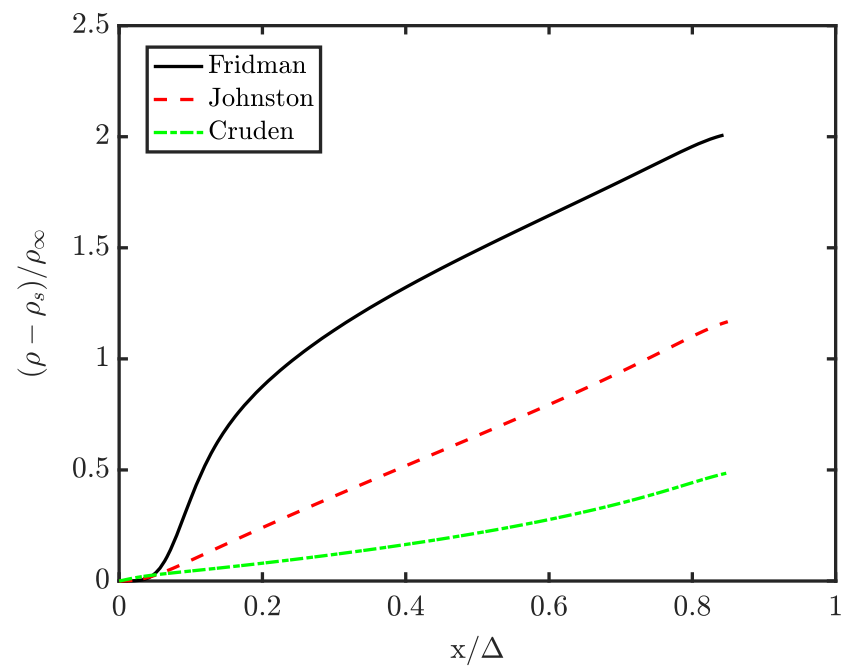

Fig. 13 Direct comparison of chemical term contributions to the total density profile for HET, MSL1-1455 1-in.-diam sphere; the frozen shock density ratio is $\rho_{s} / \rho_{\infty}=5.2$.

\section{Conclusions}

The shock standoff distances for hypervelocity $\mathrm{CO}_{2}$ flow over sphere and spherically-blunted cone geometries have been examined through theory, simulations, and experiments in two impulse facilities with different gas acceleration processes. The theoretical predictions by Hornung et al. [9] for sphere-cone standoff distance derived from perfect gas simulations have been verified using LAURA simulations for reacting carbon dioxide flow, replacing the frozen post-shock density with the average density along the stagnation streamline.

Three experiments for spheres and four for sphere-cones were analyzed using both high-speed and high-resolution images.
Experimental standoff distance data were presented, bounded by uncertainty in the experimental measurement of standoff distance as well as the chemically frozen and equilibrium limits in post-shock density. All of the data agree with the analytical predictions to within experimental uncertainty. The effect of using a conical nozzle to achieve high expansion ratio was observed for the sphere-cone shock layer, and a correction factor for flow divergence was validated. This equation can be used to evaluate the impact of a conical nozzle in past and future experiments.

The simulation data were analyzed along the stagnation streamline, and the contributions to the total density ratio from vibrational nonequilibrium, convection, chemical nonequilibrium, and the boundary layer were extracted. The largest difference between three mechanisms was observed in the chemical contribution. The Fridman mechanism predicts a larger post-shock density rise than the Johnston mechanism, with the Cruden mechanism resulting in the smallest post-shock density rise. Simulations using the Fridman mechanism produced the best agreement with the HET data. At comparable values of the total enthalpy $\left(h_{0}=5.6-6.1 \mathrm{MJ} / \mathrm{kg}\right)$ and the binaryscaling parameter $\left(\rho_{\infty}=0.3-1.8 \mathrm{~g} / \mathrm{m}^{2}\right)$, simulations of T5 experiments using all three kinetic mechanisms were in good agreement with experimental data with small differences between model predictions at these lower-density conditions. At higher density, the closest agreement with T5 experiments was obtained using the Johnston and Cruden mechanisms. These comparisons held for both sphere and sphere-cone experiments.

There was no evidence that vibrational freezing in the T5 nozzle significantly affects the shock standoff distance at any of the conditions tested. Experiments were designed to span the value of the binary-scaling parameter of the LENS I Run 8 test; however, the standoff distance discrepancy between the Run 8 data and the DPLR simulations was not reproduced [10]. A possible explanation for the standoff discrepancy found in LENS I Run 8 is early-onset driver-gas contamination at this particular test condition due to over-tailoring. With a mix of light driver gas and $\mathrm{CO}_{2}$, the standoff distance would increase. Sudani et al. experimentally showed that a slightly overtailored condition reduces the test time significantly and can induce early-onset driver-gas contamination [49].

\section{Appendix: Kinetic Rates}

The rates of the chemical models implemented in this work are shown in Tables A1-A3 for the Johnston and Brandis [20], Cruden et al. [25], and Fridman [26] kinetic models, respectively. The forward rate constants $k_{f}$ are expressed in modified Arrhenius form and given by

$$
k_{f}=A_{f} T_{a}^{\eta_{f}} \exp \left(-E_{a} / T_{a}\right)
$$

where $A_{f}$ is the pre-exponential constant (expressed in units of $\mathrm{cm}^{3} /(\mathrm{mol} \cdot \mathrm{s})$ or $\left.\mathrm{cm}^{6} /(\mathrm{mol} \cdot \mathrm{s})\right)$ depending on the number of reactants, $\eta_{f}$ is the temperature exponential constant, and $E_{a}$ is the activation energy (expressed in units of K). The conventional [17] empirical approach used to apply one-temperature reaction rates to the two-temperature model is to evaluate the rates with a geometrically averaged effective temperature:

$$
T_{a}=T^{s} T_{V}^{s-1}
$$

\begin{tabular}{|c|c|c|c|c|c|c|c|c|c|c|}
\hline \multirow[b]{2}{*}{ No. } & \multirow[b]{2}{*}{ Chemical reactions } & \multirow[b]{2}{*}{$A_{f}, \mathrm{~cm}^{3} /(\mathrm{mol} \cdot \mathrm{s})$} & \multirow[b]{2}{*}{$\eta_{f}$} & \multirow[b]{2}{*}{$E_{a}, \mathrm{~K}$} & \multirow[b]{2}{*}{$T_{a}, \mathrm{~K}$} & \multicolumn{5}{|c|}{ Multiplier } \\
\hline & & & & & & $\mathrm{CO}_{2}$ & $\mathrm{CO}$ & $\mathrm{O}_{2}$ & $\mathrm{C}$ & $\mathrm{O}$ \\
\hline 1 & $\mathrm{CO}+\mathrm{M} \rightarrow \mathrm{C}+\mathrm{O}+\mathrm{M}$ & $1.20 \mathrm{e} 21$ & -1.00 & 129,000 & $\overline{\sqrt{T T_{V}}}$ & 1.0 & 1.0 & 1.0 & 1.5 & 1.5 \\
\hline 2 & $\mathrm{CO}+\mathrm{O} \rightarrow \mathrm{O}_{2}+\mathrm{C}$ & $3.90 \mathrm{e} 13$ & -0.18 & 69,200 & $T$ & -- & -- & -- & -- & -- \\
\hline 3 & $\mathrm{CO}_{2}+\mathrm{M} \rightarrow \mathrm{CO}+\mathrm{O}+\mathrm{M}$ & $6.90 \mathrm{e} 21$ & -1.50 & 63,275 & $\sqrt{T T_{V}}$ & 1.0 & 1.0 & 1.0 & 2.0 & 2.0 \\
\hline 4 & $\mathrm{CO}_{2}+\mathrm{O} \rightarrow \mathrm{O}_{2}+\mathrm{CO}$ & $2.71 \mathrm{e} 14$ & 0.00 & 33,797 & $T$ & -- & -- & -- & -- & -- \\
\hline 5 & $\mathrm{O}_{2}+\mathrm{M} \rightarrow 2 \mathrm{O}+\mathrm{M}$ & $2.00 \mathrm{e} 21$ & -1.50 & 59,360 & $T^{0.7} T_{V}^{0.3}$ & 1.0 & 1.0 & 1.0 & 5.0 & 5.0 \\
\hline
\end{tabular}

Table A1 Johnston and Brandis kinetic model [20] 
Table A2 Cruden et al. kinetic model [25]

\begin{tabular}{|c|c|c|c|c|c|c|c|c|c|c|}
\hline \multirow[b]{2}{*}{ No. } & \multirow[b]{2}{*}{ Chemical reactions } & \multirow[b]{2}{*}{$A_{f}, \mathrm{~cm}^{3} /(\mathrm{mol} \cdot \mathrm{s})$} & \multirow[b]{2}{*}{$\eta_{f}$} & \multirow[b]{2}{*}{$E_{a}, \mathrm{~K}$} & \multirow[b]{2}{*}{$T_{a}, \mathrm{~K}$} & \multicolumn{5}{|c|}{ Multiplier } \\
\hline & & & & & & $\overline{\mathrm{CO}_{2}}$ & $\mathrm{CO}$ & $\mathrm{O}_{2}$ & $\mathrm{C}$ & $\mathrm{O}$ \\
\hline$\overline{1}$ & $\mathrm{CO}+\mathrm{M} \rightarrow \mathrm{C}+\mathrm{O}+\mathrm{M}$ & $7.99 \mathrm{e}+38$ & -5.50 & 129,060 & $T$ & 1.0 & 1.0 & 1.0 & 1.0 & 1.0 \\
\hline 2 & $\mathrm{CO}+\mathrm{O} \rightarrow \mathrm{O}_{2}+\mathrm{C}$ & $3.90 \mathrm{e}+13$ & -0.18 & 69,200 & $T$ & -- & - & -1 & - & - - \\
\hline 3 & $\mathrm{CO}_{2}+\mathrm{M} \rightarrow \mathrm{CO}+\mathrm{O}+\mathrm{M}$ & $7.47 \mathrm{e} 12$ & 0.50 & 52,321 & $T$ & 1.0 & 1.0 & 1.0 & 1.0 & 1.0 \\
\hline 4 & $\mathrm{CO}_{2}+\mathrm{O} \rightarrow \mathrm{O}_{2}+\mathrm{CO}$ & $2.71 \mathrm{e} 14$ & 0.00 & 33,797 & $T$ & -- & - & - & - & - - \\
\hline 5 & $\mathrm{O}_{2}+\mathrm{M} \rightarrow 2 \mathrm{O}+\mathrm{M}$ & $1.20 \mathrm{e} 14$ & 0.00 & 54,246 & $T$ & 1.0 & 1.0 & 1.0 & 1.0 & 1.0 \\
\hline
\end{tabular}

Table A3 Fridman kinetic model [26]

\begin{tabular}{lccccc}
\hline \hline No. & Elementary chemical reactions & $A_{f}, \mathrm{~cm}^{3} /(\mathrm{mol} \cdot \mathrm{s}) \mathrm{or} \mathrm{cm}^{6} /\left(\mathrm{mol}^{2} \cdot \mathrm{s}\right)$ & $\eta_{f}$ & $E_{a}, \mathrm{~K}$ & $T_{a}, \mathrm{~K}$ \\
\hline 1 & $\mathrm{CO}_{2}+\mathrm{CO}_{2} \rightarrow \mathrm{CO}+\mathrm{O}+\mathrm{CO}_{2}$ & $2.64 \mathrm{e} 17$ & 0.0 & 64,717 & $T_{V}$ \\
2 & $\mathrm{CO}_{2}+\mathrm{CO} \rightarrow \mathrm{CO}+\mathrm{O}+\mathrm{CO}$ & $2.64 \mathrm{e} 17$ & 0.0 & 64,717 & $T_{V}$ \\
3 & $\mathrm{CO}_{2}+\mathrm{O}_{2} \rightarrow \mathrm{CO}+\mathrm{O}+\mathrm{O}_{2}$ & $2.24 \mathrm{e} 14$ & 0.0 & 60,185 & $T_{V}$ \\
4 & $\mathrm{CO}+\mathrm{O}+\mathrm{CO}_{2} \rightarrow \mathrm{CO}_{2}+\mathrm{CO}_{2}$ & $3.94 \mathrm{e}-12$ & 0.0 & 2,164 & $T$ \\
5 & $\mathrm{CO}+\mathrm{O}+\mathrm{CO} \rightarrow \mathrm{CO}_{2}+\mathrm{CO}$ & $3.94 \mathrm{e}-12$ & 0.0 & 2,164 & $T$ \\
6 & $\mathrm{CO}+\mathrm{O}+\mathrm{O}_{2} \rightarrow \mathrm{CO}_{2}+\mathrm{O}_{2}$ & $3.92 \mathrm{e}-12$ & 0.0 & $-1,862$ & $T$ \\
7 & $\mathrm{O}+\mathrm{CO}_{2} \rightarrow \mathrm{CO}+\mathrm{O}_{2}$ & $4.68 \mathrm{e} 12$ & 0.0 & 16,606 & $\sqrt{T T_{V}}$ \\
8 & $\mathrm{CO}+\mathrm{O}_{2} \rightarrow \mathrm{CO}+\mathrm{O}$ & 0.0 & 12,681 & $T$ \\
9 & $\mathrm{O}_{2}+\mathrm{O}_{2} \rightarrow \mathrm{O}+\mathrm{O}+\mathrm{O}_{2}$ & $4.41 \mathrm{e} 11$ & 0.0 & 59,682 & $T_{V}$ \\
10 & $\mathrm{O}_{2}+\mathrm{O} \rightarrow \mathrm{O}+\mathrm{O}+\mathrm{O}$ & 0.0 & 57,820 & $T_{V}$ \\
11 & $\mathrm{O}_{2}+\mathrm{CO} \rightarrow \mathrm{O}+\mathrm{O}+\mathrm{CO}_{12}$ & $1.20 \mathrm{e} 16$ & 0.0 & 59,380 & $T_{V}$ \\
12 & $\mathrm{O}_{2}+\mathrm{CO} \rightarrow \mathrm{O}+\mathrm{O}+\mathrm{CO}_{2}$ & $1.45 \mathrm{e} 15$ & 0.0 & 56,109 & $T_{V}$ \\
13 & $\mathrm{O}+\mathrm{O}+\mathrm{O}_{2} \rightarrow \mathrm{O}_{2}+\mathrm{O}_{2}$ & $1.55 \mathrm{e} 15$ & 0.0 & 0 & $T$ \\
14 & $\mathrm{O}+\mathrm{O}+\mathrm{O} \rightarrow \mathrm{O}_{2}+\mathrm{O}$ & $4.10 \mathrm{e}-10$ & 0.0 & $-2,265$ & $T$ \\
15 & $\mathrm{O}+\mathrm{O}+\mathrm{CO} \rightarrow \mathrm{O}_{2}+\mathrm{CO}_{10}$ & $1.32 \mathrm{e}-9$ & 0.0 & 0 & $T$ \\
16 & $\mathrm{O}+\mathrm{O}+\mathrm{CO}_{2} \rightarrow \mathrm{O}_{2}+\mathrm{CO}_{2}$ & $1.66 \mathrm{e}-10$ & 0.0 & 0 & $T$ \\
\hline \hline
\end{tabular}

where $s$ is between 0 and 1 . The Cruden and Johnston rates satisfy thermodynamic consistency, with the backward rate constant $k_{b}$ determined from the equilibrium constant based on concentration. The backward rate constant for the Fridman chemistry model is provided in Arrhenius form.

\section{Acknowledgments}

This work was supported in part by the NASA Space Technology Research Fellowships NNX14AM59H and NASA awards NNX14AO97A and NNX16AO55G. The authors gratefully acknowledge Hans Hornung and Joseph Shepherd at the California Institute of Technology; Brett Cruden, Dinesh Prabhu, Aaron Brandis, and Michael Barnhardt at NASA Ames Research Center; and Brian Hollis and Chris Johnston at NASA Langley Research Center for their valuable discussion and suggestions.

\section{References}

[1] Hayes, W. D., and Probstein, R. F., Hypersonic Flow Theory, Academic Press, New York, 1959, Chap. 4.

[2] Van Dyke, M. D., "The Supersonic Blunt-Body Problem-Review and Extension," Journal of Aerospace Sciences, Vol. 25, No. 8, 1958, pp. 485-496.

https://doi.org/10.2514/8.7744

[3] Lobb, R. K., "Experimental Measurement of Shock Detachment Distance on Spheres Fired in Air at Hypervelocities," The High Temperature Aspects of Hypersonic Flow, AGARDograph, Vol. 68, 1964, pp. 519-527; also Proceedings of the AGARD-NATO Specialist Meeting, Belgium, 1962. https://doi.org/10.1016/B978-1-4831-9828-6.50031-X

[4] Hornung, H. G., "Non-Equilibrium Dissociating Flow over Spheres and Circular Cylinders," Journal of Fluid Mechanics, Vol. 53, No. 1, 1972, pp. 149-176. https://doi.org/10.1017/S0022112072000084
[5] Stulov, V. P., "Similarity Law for Supersonic Flow Past Blunt Bodies," Fluid Dynamics, Vol. 4, No. 4, 1969, pp. 93-96. https://doi.org/10.1007/BF01094695

[6] Wen, C. Y., and Hornung, H. G., "Non-Equilibrium Dissociating Flow over Spheres," Journal of Fluid Mechanics, Vol. 299, Sept. 1995, pp. 389-405. https://doi.org/10.1017/S0022112095003545

[7] Gnoffo, P. A., Weilmuenster, J. K., Braun, R. D., and Cruz, C. I., "Influence of Sonic-Line Location on Mars Pathfinder Probe Aerothermodynamics," Journal of Spacecraft and Rockets, Vol. 33, No. 2, 1996, pp. 169-177. https://doi.org/10.2514/3.26737

[8] Gnoffo, P. A., Braun, R. D., Weilmuenster, K. J., Mitcheltree, R. A., Engelund, W. C., and Powell, R. C., "Prediction and Validation of Mars Pathfinder Hypersonic Aerodynamic Database," Journal of Spacecraft and Rockets, Vol. 36, No. 3, 1999, pp. 367-373. https://doi.org/10.2514/2.3455

[9] Hornung, H. G., Schramm, J. M., and Hannemann, K., "Hypersonic Flow over Spherically Blunted Cone Capsules for Atmospheric Entry. Part 1. The Sharp Cone and the Sphere," Journal of Fluid Mechanics, Vol. 871, July 2019, pp. 1097-1116. https://doi.org/10.1017/jfm.2019.342

[10] MacLean, M., and Holden, M., "Numerical Assessment of Data in Catalytic and Transitional Flows for Martian Entry," AIAA Paper 2006-2946, June 2006. https://doi.org/10.2514/6.2006-2946

[11] Rock, S. G., Candler, G. V., and Hornung, H. G., "Analysis of Thermochemical Nonequilibrium Models for Carbon Dioxide Flows," AIAA Journal, Vol. 31, No. 12, 1993, pp. 2255-2262. https://doi.org/10.2514/3.11923

[12] Wright, M. J., Olejniczak, J., Brown, J. L., Hornung, H. G., and Edquist, K. T., "Modeling of Shock Tunnel Aeroheating Data on the Mars Science Laboratory Aeroshell," Journal of Thermophysics and Heat Transfer, Vol. 20, No. 4, 2006, pp. 641-651. https://doi.org/10.2514/1.19896

[13] MacLean, M., Wadhams, T., MacLean, M., Mundy, E., and Parker, R., "Experimental Studies in LENS I and X to Evaluate Real Gas Effects on 
Hypervelocity Vehicle Performance," AIAA Paper 2007-0204, Jan. 2007.

https://doi.org/10.2514/6.2007-204

[14] Sharma, M., Swantek, A. B., Flaherty, W., Austin, J. M., Doraiswamy, S., and Candler, G. V., "Experimental and Numerical Investigation of Hypervelocity Carbon Dioxide Flow over Blunt Bodies," Journal of Thermophysics and Heat Transfer, Vol. 24, No. 4, 2010, pp. 673-683. https://doi.org/10.2514/1.49386

[15] MacLean, M., Dufrene, A., Carr, Z., Parker, R., and Holden, M., "Measurements and Analysis of Mars Entry, Descent, and Landing Aerothermodynamics at Flight-Duplicated Enthalpies in LENS-XX Expansion Tunnel," AIAA Paper 2015-1897, Jan. 2015. https://doi.org/10.2514/6.2015-1897

[16] Park, C., Jaffe, J., Howe, J., and Candler, G., "Chemical Kinetic Problems of Future NASA Missions," AIAA Paper 1991-0464, Jan. 1991.

[17] Park, C., Nonequilibrium Hypersonic Aerothermodynamics, Wiley, New York, 1990, p. 114.

[18] Doraiswamy, S., Kelley, J., and Candler, G. V., "Vibrational Modeling of $\mathrm{CO}_{2}$ in High-Enthalpy Nozzle Flows," Journal of Thermophysics and Heat Transfer, Vol. 24, No. 1, 2010, pp. 9-17. https://doi.org/10.2514/1.43280

[19] Hollis, B. R., and Prabhu, D. K., "Assessment of Laminar, Convective Aeroheating Prediction Uncertainties for Mars Entry Vehicles," Journal of Spacecraft and Rockets, Vol. 50, No. 1, 2013, pp. 56-68. https://doi.org/10.2514/1.A32257

[20] Johnston, C. O., and Brandis, A. M., "Modeling of Nonequilibrium CO Fourth-Positive and CN Violet Emission in $\mathrm{CO}_{2}-\mathrm{N}_{2}$ Gases," Journal of Quantitative Spectroscopy and Radiative Transfer, Vol. 149, Dec. 2014, pp. 303-317. https://doi.org/10.1016/j.jqsrt.2014.08.025

[21] Hollis, B. R., Prabhu, D. K., Maclean, M., and Dufrene, A., "BluntBody Aerothermodynamic Database from High-Enthalpy CarbonDioxide Testing in an Expansion Tunnel," Journal of Thermophysics and Heat Transfer, Vol. 31, No. 3, 2017, pp. 712-731. https://doi.org/10.2514/1.T5019

[22] Edquist, K. T., Dyakonov, A. A., Wright, M. J., and Tang, C., "Aerothermodynamic Environments Definition for the Mars Science Laboratory Entry Capsule," AIAA Paper 2007-1206, Jan. 2007. https://doi.org/10.2514/6.2007-1206

[23] Brandis, A. M., White, T. R., Saunders, D. A., Hill, J. P., and Johnston, C., "Simulation of the Schiaparelli Entry and Comparison to Aerothermal Flight Data," AIAA Paper 2019-3260, June 2019. https://doi.org/10.2514/6.2019-3260

[24] Alireza, M., Gnoffo, P. A., Johnston, C. O., and Kleb, W. L., "LAURA Users Manual: 5.5-64987," NASA TM-2013-217800, 2013.

[25] Cruden, B. A., Brandis, A. M., and MacDonald, M. E., "Characterization of CO Thermochemistry in Incident Shockwaves," AIAA Paper 2018-3768, June 2018. https://doi.org/10.2514/6.2018-3768

[26] Fridman, A., Plasma Chemistry, Cambridge Univ. Press, New York, 2008, p. 278.

[27] Hornung, H., "Performance Data of the New Free-Piston Shock Tunnel at GALCIT," AIAA Paper 1992-3943, July 1992. https://doi.org/10.2514/6.1992-3943

[28] Browne, S., Zeigler, J., Bitter, N., Schmidt, B., Lawson, J., and Shepherd, J. E., "Numerical Solution Methods for Shock and Detonation Jump Conditions," California Inst. of Technology, GALCIT Rept. gm2018.001 revised 2019, Pasadena, CA, 2019.

[29] Jewell, J. S., "Boundary-Layer Transition on a Slender Cone in Hypervelocity Flow with Real Gas Effects," Ph.D. Thesis, California Inst. of Technology, Pasadena, CA, 2014.

[30] Candler, G. V., "Hypersonic Nozzle Analysis Using an Excluded Volume Equation of State," AIAA Paper 2005-5202, June 2005. https://doi.org/10.2514/6.2005-5202

[31] Camac, M., " $\mathrm{CO}_{2}$ Relaxation Processes in Shock Waves," Fundamental Phenomena in Hypersonic Flow, Cornell Univ. Press, New York, 1964, pp. 195-215.
[32] Wagnild, R. M., "High Enthalpy Effects on Two Boundary Layer Disturbances in Supersonic and Hypersonic Flow," Ph.D. Thesis, Univ. of Minnesota, Minneapolis, MN, 2014.

[33] Leibowitz, M. G., and Austin, J. M., "Assessment of Reflected Shock Tunnels for Mars Entry Vehicle Ground Testing," AIAA Paper 20181721, Jan. 2018 https://doi.org/10.2514/6.2018-1721

[34] Leibowitz, M. G., "Hypervelocity Shock Tunnel Studies of Blunt Body Aerothermodynamics in Carbon Dioxide for Mars Entry," Ph.D. Thesis, California Inst. of Technology, Pasadena, CA, 2020.

[35] Hornung, H. G., "Effect of Conical Free Stream on Shock Stand-Off Distance," AIAA Journal, Vol. 57, No. 9, 2019, pp. 4115-4116. https://doi.org/10.2514/1.J058385

[36] Quirk, J. J., "AMRITA-A Computational Facility (for CFD Modelling)," VKI CFD, Vol. 29, Lecture Series, Von Karman Inst., 1998.

[37] Levya, I. A., "Shock Detachment Process on Cones in Hypervelocity Flow," Ph.D. Thesis, California Inst. of Technology, Pasadena, CA, 1999.

[38] Dufrene, A., Sharma, M., and Austin, J. M., "Design and Characterization of a Hypervelocity Expansion Tube Facility," Journal of Propulsion and Power, Vol. 23, No. 6, 2007, pp. 1185-1193. https://doi.org/10.2514/1.30349

[39] Massa, L., and Austin, J. M., "Spatial Linear Stability of a Hypersonic Shear Layer with Nonequilibrium Thermochemistry," Physics of Fluids, Vol. 20, No. 8, 2008, Paper 084104. https://doi.org/10.1063/1.2972937

[40] Gnoffo, P., Gupta, R., and Shinn, J., "Conservation Equations and Physical Models for Hypersonic Air Flows in Thermal and Chemical Nonequilibrium," NASA TP-2867, 1989.

[41] Cruden, B. A., Brandis, A. M., and Prabhu, D. K., "Measurement and Characterization of Mid-Wave Infrared Radiation in $\mathrm{CO}_{2}$ Shocks," AIAA Paper 2014-2962, June 2014. https://doi.org/10.2514/6.2014-2962

[42] Millikan, R. C., and White, D. R., "Systematics of Vibrational Relaxation," Journal of Chemical Physics, Vol. 39, No. 12, 1963, pp. 3209-3213. https://doi.org/10.1063/1.1734182

[43] Park, C., Howe, J., Jaffe, R., and Candler, G., "Review of ChemicalKinetic Problems of Future NASA Missions, II: Mars Entries," Journal of Thermophysics and Heat Transfer, Vol. 8, No. 1, 1994, pp. 9-23. https://doi.org/10.2514/3.496

[44] Parziale, N. J., Schmidt, B. E., Wang, P. S., Hornung, H. G., and Shepherd, J. E., "Pulsed Laser Diode for Use as a Light Source for Short-Exposure, High-Frame-Rate Flow Visualization," AIAA Paper 2015-0530, Jan. 2015. https://doi.org/10.2514/6.2015-0530

[45] Marineau, E. C., and Hornung, H. G., "Study of Bow-Shock Wave Unsteadiness in Hypervelocity Flow from Reservoir Fluctuations," AIAA Paper 2010-382, Jan. 2010. https://doi.org/10.2514/6.2010-382

[46] Vincenti, W. G., and Kruger, C. H., Jr., Introduction to Physical Gas Dynamics, Wiley, New York, 1965, Chap. VII.

[47] Houwing, A. F. P., Nonaka, S., Mizuno, H., and Takayama, K., "Effects of Vibrational Relaxation on Bow Shock Standoff Distance for Nonequilibrium Flows," AIAA Journal, Vol. 38, No. 9, 2000, pp. 1760-1763. https://doi.org/10.2514/2.1167

[48] Goodwin, D. G., Speth, R. L., Moffat, H. K., and Weber, B. W., "Cantera: an Object-Oriented Software Toolkit for Chemical Kinetics, Thermodynamics, and Transport Processes," Ver. 2.4.0, https://www .cantera.org [retrieved 24 Aug. 2018]. https://doi.org/10.5281/zenodo. 1174508

[49] Sudani, N., Valiferdowsi, B., and Hornung, H. G., "Test Time Increase by Delaying Driver Gas Contamination for Reflected Shock Tunnels," AIAA Journal, Vol. 38, No. 9, 2000, pp. 1497-1503. https://doi.org/10.2514/2.1138

M. M. Choudhari Associate Editor 